\title{
BRG1 knockdown inhibits proliferation through multiple cellular pathways in prostate cancer
}

\author{
Katherine A. Giles ${ }^{1,2,3}$, Cathryn M. Gould', Joanna Achinger-Kawecka1,4, Scott G. Page ${ }^{2}$, Georgia R. Kafer², \\ Samuel Rogers ${ }^{2}$, Phuc-Loi Luu ${ }^{1,4}$, Anthony J. Cesare ${ }^{2}$, Susan J. Clark ${ }^{1,4+}$ and Phillippa C. Taberlay ${ }^{3^{*}+(0)}$
}

\begin{abstract}
Background: BRG1 (encoded by SMARCA4) is a catalytic component of the SWI/SNF chromatin remodelling complex, with key roles in modulating DNA accessibility. Dysregulation of BRG1 is observed, but functionally uncharacterised, in a wide range of malignancies. We have probed the functions of BRG1 on a background of prostate cancer to investigate how BRG1 controls gene expression programmes and cancer cell behaviour.

Results: Our investigation of SMARCA4 revealed that BRG1 is over-expressed in the majority of the 486 tumours from The Cancer Genome Atlas prostate cohort, as well as in a complementary panel of 21 prostate cell lines. Next, we utilised a temporal model of BRG1 depletion to investigate the molecular effects on global transcription programmes. Depleting BRG1 had no impact on alternative splicing and conferred only modest effect on global expression. However, of the transcriptional changes that occurred, most manifested as down-regulated expression. Deeper examination found the common thread linking down-regulated genes was involvement in proliferation, including several known to increase prostate cancer proliferation (KLK2, PCAT1 and VAV3). Interestingly, the promoters of genes driving proliferation were bound by BRG1 as well as the transcription factors, AR and FOXA1. We also noted that BRG1 depletion repressed genes involved in cell cycle progression and DNA replication, but intriguingly, these pathways operated independently of AR and FOXA1. In agreement with transcriptional changes, depleting BRG1 conferred G1 arrest.
\end{abstract}

Conclusions: Our data have revealed that BRG1 promotes cell cycle progression and DNA replication, consistent with the increased cell proliferation associated with oncogenesis.

Keywords: BRG1, SMARCA4, Chromatin remodelling, Cancer, Gene expression, Cell cycle, Transcription, DNA replication

\section{Background}

Nucleosomes serve as a physical backbone for chromatin organisation on a global scale and at local gene regulatory elements. Nucleosomes therefore govern both genome-wide stability and local DNA accessibility [1].

\footnotetext{
*Correspondence: phillippa.taberlay@utas.edu.au

${ }^{\dagger}$ Susan J. Clark and Phillippa C. Taberlay contributed equally to this work

${ }^{3}$ Tasmanian School of Medicine, College of Health and Medicine, University of Tasmania, TAS, Hobart 7000, Australia

Full list of author information is available at the end of the article
}

Nucleosome positioning by ATP-dependent chromatin remodellers plays a critical role in regulating DNA accessibility and allows genes to be expressed at the appropriate place and time [1]. Genomic profiling has demonstrated that dynamic regulation of DNA accessibility occurs primarily at DNA regulatory elements, which are cell type specific, and that DNA accessibility changes reflect concomitant transcriptional patterns $[2,3]$. It is essential for chromatin to be relaxed at active gene promoters to create an ordered nucleosome disassembly, which permits binding of RNA pol II and the 
general transcription machinery [4, 5]. In agreement, ChIP-seq data show that transcription factors are concentrated on accessible DNA, with the highest levels of bound transcription factors correlating with the most accessible genomic regions [6]. Conversely, chromatin condensation resulting in reduced DNA accessibility is necessary for transcriptional repression [7]. Disruption to the DNA accessibility landscape is a feature of cancer $[2,8,9]$. This was recently emphasised in genomic sequencing data from multiple cancers and cancer subtypes, which revealed associations between the accessible chromatin organisation and mutation load [8]. Moreover, studies of aged human and yeast cells demonstrated that nucleosome loss compromises genome stability, gene regulation and transcription [10, 11].

Genes encoding ATP-dependent chromatin remodellers are themselves frequently mutated and often atypically expressed in cancer [5, 12-16]. Notably, the SWI/ SNF (switch/sucrose non-fermentable) chromatin remodelling complex is mutated or transcriptionally deregulated in $20 \%$ of cancers; a mutation frequency approaching that of TP53 ( 26\%) $[12,14,17]$. The SWI/ SNF complex is often described as a tumour suppressor because it is required by the Retinoblastoma protein $(\mathrm{Rb})$ family for regulation of normal cell growth $[18,19]$. Disruptions of multiple SWI/SNF subunits are reported in human tumours and cell lines [13-15, 20-37], often accompanied by a loss of heterozygosity consistent with the inactivation of a tumour suppressor [13, 34]. The specific SWI/SNF mutations observed in tumours and the cancers associated with altered SWI/SNF function have been extensively reviewed [12-15, 26, 31, 34, 38]. However, the mechanism and functional consequences of SWI/SNF dysregulation are still being defined.

Brahma-related gene 1 (BRG1) is one of the two mutually exclusive ATPases within the SWI/SNF complex. Interestingly, SMARCA4 (SWI/SNF-related, matrixassociated, actin-dependent regulator of chromatin, Subfamily A, Member 4), the gene encoding BRG1, has been observed in both down- and up-regulated states in cancer, indicative of the diverse and complex BRG1 functions. SMARCA4 mRNA was seen to be down-regulated in bladder, colon, non-triple negative breast cancers, head and neck, oesophageal, melanoma, pancreatic, lung and ovarian cancers, and SMARCA4 mutation rates in these cancers have been reported between 4 and $13 \%$ [12-14, 22, 24, 30, 39-41]. In contrast, SMARCA4 has been reported as over expressed in cancers of the prostate, triple negative breast cancers and some leukaemias [12, 22, 24, 30, 42, 43]. In SMARCA4 over expressing cancers, no significant recurrent mutations have been reported [42, 44-46]. The importance of BRG1 in cancer is further evidenced through studies of synthetic lethality, where BRG1 was observed to have a synthetic lethal relationship with the alternative SWI/SNF ATPase Braham (BRM), and Aurora A kinase in lung cancer, and PTEN in prostate cancer $[43,47,48]$.

Examination of multiple prostate cancer cohorts has demonstrated elevated SMARCA4 expression or increased BRG1 protein levels. Clinical studies of primary prostate tumours reported an overall increase in BRG1 protein by immunohistochemistry [42-46], and increased SMARCA4 gene expression has been reported in tumours from The Cancer Genome Atlas (TCGA) prostate cancer cohort compared to normal prostate tissue $[49,50]$. Moreover, higher SMARCA4 gene expression or increased BRG1 protein levels are inversely correlated with patient survival $[43,49]$. While it is established that BRG1 is commonly up-regulated in prostate cancer, the full range of molecular pathways impacted by dysregulated BRG1 levels and the contribution of these molecular changes to the atypical phenotype of prostate cancer cells remains unclear.

BRG1 has known roles in regulating DNA for temporal gene expression at both promoters and enhancer gene regulatory elements [4, 51-56]. Moreover, BRG1 maintains the epigenetic landscape of a cell at these gene regulatory elements. Specifically, BRG1 has been directly linked to transcriptional output through its recognition of H3K14ac [57-59]. In the absence of H3K14ac, BRG1 is still present at promoters and histones are disassembled from the chromatin; however, transcription is reduced [60]. At enhancers, BRG1 depletion greatly reduces $\mathrm{H} 3 \mathrm{~K} 27 \mathrm{ac}$ and subtlety reduces $\mathrm{H} 3 \mathrm{~K} 4 \mathrm{me} 1$, which is correlated with a decrease in chromatin accessibility [53]. BRG1 is also known to mediate inter-chromosomal looping interactions between specific loci such as the $M Y C$ enhancer and promoter, the alpha-globulin genes, the $I g H$ locus and the class II major histocompatibility complex gene locus [24, 61-64]. On a global scale, BRG1 binding has been found at DNA-loop anchors [56] and topological associated domain (TAD) boundaries where it increases their stability [65]. Together, this demonstrates an important role for BRG1 in maintaining chromatin architecture at both local and global levels for transcription regulation.

Here, we dissected the molecular role of BRG1 on the transcriptome in prostate cancer. We confirmed that SMARCA4 is over-expressed in prostate cancer irrespective of molecular subtype, and identified SMARCA4 was also over expressed in a panel of prostate cancer cell lines. Depletion of BRG1 in LNCaP prostate cancer cells resulted in a modest effect on global gene transcription with most changes resulting in down-regulated gene expression. Within the cohort of down-regulated genes in BRG1 depleted cells, we identified gene clusters 
defined by their co-occupancy or independence from the androgen receptor (AR) and Forkhead box A1 (FOXA1) transcription factors, both of which are known BRG1 co-activators [66-68]. Our data revealed that BRG1, AR and FOXA1 co-regulate known prostate cancer genes $K L K 2, P C A T 1$ and $V A V 3$. Gene ontology analysis further revealed that genes regulated by BRG1 independent of $\mathrm{AR}$ and FOXA1 include factors regulating cell cycle and proliferation processes including DNA replication. In agreement, depleting BRG1 promoted G1 arrest resulting in reduced cell proliferation. Cumulatively, the data indicate that BRG1 promotes expression of cellular proliferation factors and cancer-associated genes in prostate cancer cells.

\section{Results}

SMARCA4 is over expressed in prostate cancer irrespective of molecular subtype

We first examined the expression of SMARCA4 in the TCGA [50] prostate normal and cancer cohort. The 486 tumour samples were subset into the seven TCGA categorised molecular subtypes of prostate cancer [50]. These included those with fusion genes involving ERG (46\%), ETV1 (8\%), ETV4 (4\%) and FLI1 (1\%), or those with mutations in SPOP (11\%), FOXA1 (3\%) or IDH1 (1\%) [50]. The remaining samples were grouped as 'other' (26\%). Each subtype exhibited a statistically significant increase in SMARCA4 expression $(p<0.05)$ with the exception of the 'FLI1' subtype $(p=0.5899)$ and 'other' $(p=0.1899)$, which both demonstrated a non-significant increase in SMARCA4 expression (Fig. 1a). Previous work examining SMARCA4 expression in the TCGA prostate cancer cohort demonstrated that it is also up-regulated irrespective of Gleason score [49]. Therefore, we conclude that at the mRNA level, SMARCA4 is universally over-expressed in prostate cancer, regardless of clinical grade or molecular subtype.

\section{SMARCA4 is over expressed in prostate cancer and transformed prostate cell lines}

We next examined both BRG1 protein and SMARCA4 gene expression levels in normal prostate epithelial cells (PrEC) and compared to LNCaP (lymph node metastasis), an androgen-sensitive prostate cancer cell line, as well as PC3 (bone metastasis), an androgeninsensitive prostate cancer cell line. We found that SMARCA4 gene expression was increased $\sim$ ninefold in LNCaP cells and $\sim$ sixfold in PC3 compared to PrEC $(p<0.001$; Fig. 1b). Further, the BRG1 protein level was increased $\sim 20$ and $\sim 24$ fold, respectively, in each of the prostate cancer cell lines compared to PrEC (Fig. 1c). We compared this to published RNA-seq data of several normal, cancer and transformed prostate cell lines
[69]. The mean expression of SMARCA4 was significantly increased in both the cancer cell lines and the transformed cell lines compared to the normal cells $(p=0.0148$ and $p=0.0353$, respectively; Fig. 1d). The exception was DU145 cells that has a known frameshift mutation in SMARCA4, resulting in reduced expression [36]. These data show that common prostate cancer cell lines reflect the same pattern of increased BRG1 protein that is observed in prostate tumours compared to normal prostate samples and therefore provides an appropriate model system to explore the functional consequences of BRG1 dysregulation on the transcriptome.

\section{BRG1 is required for the maintenance of active gene expression}

Our previous work has shown that BRG1 occupancy is enriched at active promoter and enhancer gene regulatory elements in LNCaP cells [56]. We therefore hypothesised that BRG1 would play an important role in maintaining the transcriptional profile of these cells. To assess this, we depleted the level of BRG1 protein using two independent siRNAs targeting SMARCA4 (si-SMARCA4-1 and si-SMARCA4-2) and performed RNA-seq at 72 and $144 \mathrm{~h}$ post-transfection (Fig. 2a). Our RNA-seq data confirmed successful depletion of the SMARCA4 transcript $(\sim 80 \%)$ at both time points (Fig. 2b). To confirm a decrease in BRG1 function, we performed a Western blot for BRG1 protein levels. We found BRG1 protein levels reduced to $50 \%$ of the non-targeting control at $72 \mathrm{~h}$, and to $\sim 20 \%$ of the nontargeting control at $144 \mathrm{~h}$ post-transfection (Fig. 2c, d). We note that there were no significant changes detected in the gene expression of any other SWI/SNF subunit proteins (Additional file 1: Figure 1A). Further quality assessment of the RNA-seq data through a principal component analysis demonstrated that the samples separated by time-point on the first dimension, accounting for $43.39 \%$ of the sample variance (Additional file 1: Figure 1B). We performed a differential gene expression analysis and identified 169 down-regulated genes and 24 up-regulated genes $(\log \mathrm{FC}>1.5, \mathrm{FDR}<0.05)$ at $72 \mathrm{~h}$ post BRG1 depletion (Fig. 2e). This increased to 800 downregulated genes and 174 up-regulated genes by $144 \mathrm{~h}$ post-transfection (Fig. 2f). This suggests that the primary role of BRG1 in LNCaP cells is to maintain active gene expression of a subset of genes.

\section{BRG1 does not function in the regulation of alternative splicing}

The nucleosome barrier within genes is reported to contribute to alternative splicing, where there is a higher conservation of nucleosomes at the splice sites of constitutive exons compared to skipped exons [70-72]. 

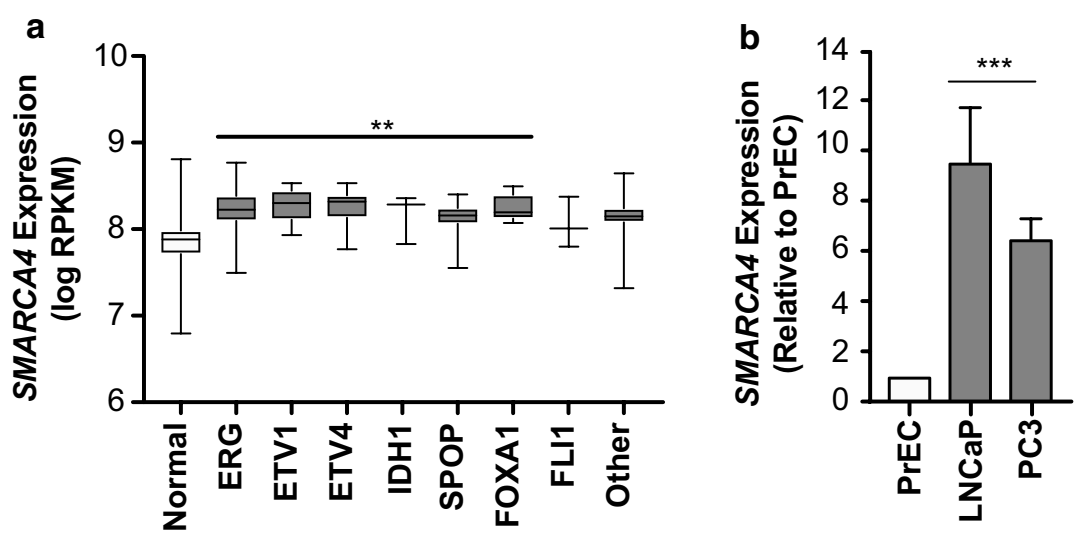

C

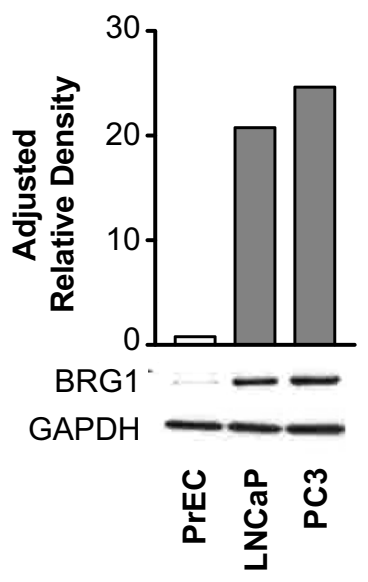

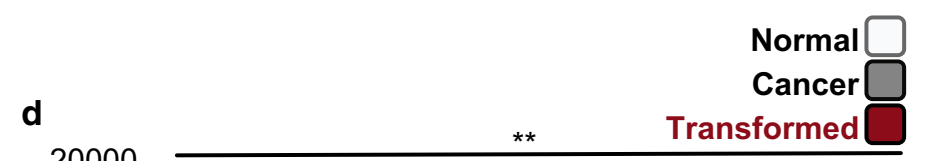

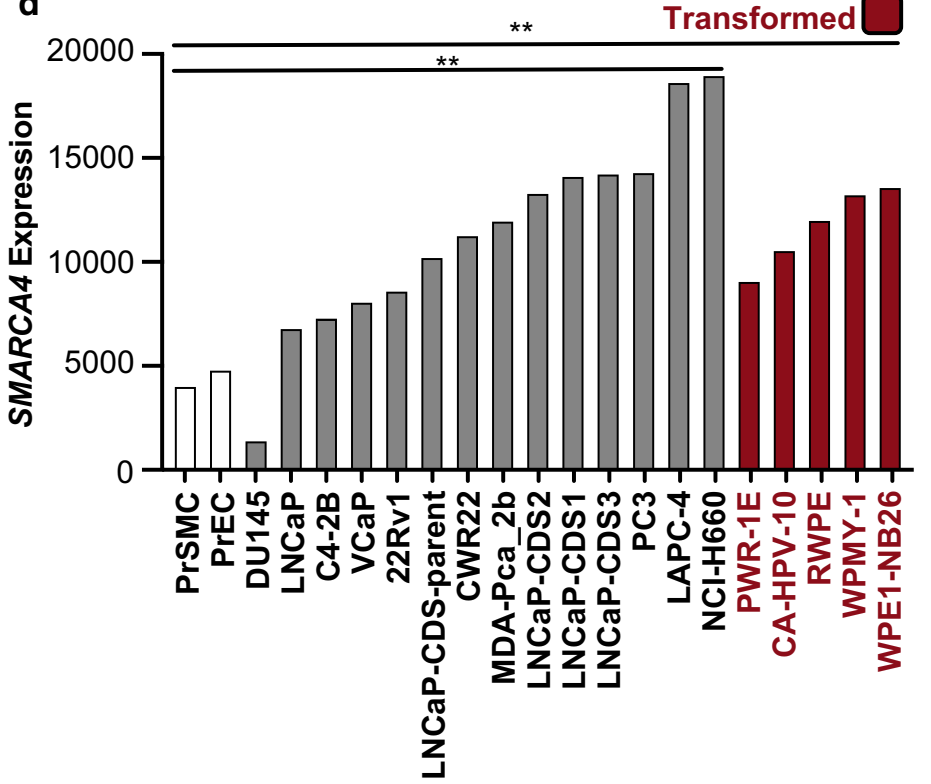

Fig. 1 SMARCA4 (BRG1) is over expressed in prostate cancer. a SMARCA4 gene expression (logPRKM) in TCGA data (tumours $n=486$, normal = 52) with tumour samples separated by molecular subtype defined by the TCGA. SMARCA4 expression is increased across all groups, with subtypes ERG, ETV1, ETV4, IDH1, SPOP and FOXA1 all significantly up-regulated, one-way ANOVA Dunnett's multiple comparison correction ${ }^{*} p<0.05$. $\mathbf{b}$ SMARCA4 gene expression in prostate cell lines normalised to 185 and relative to $\operatorname{PrEC}(n=2)$. Significance determined by one-way ANOVA with Tukey's multiple comparison correction ${ }^{* *} p<0.001$. Bars denote mean, and error bars are SD. $\mathbf{c}$ Representative Western blot of BRG1 protein level in prostate cell lines. Quantification above Western blot by adjusted relative density normalised to GAPDH and relative to PrEC. $\mathbf{d}$ Expression of SMARCA4 from RNA-seq in prostate cell lines grouped as normal, cancer or transformed. The mean of each group was calculated, and a significance was tested by one-way ANOVA Dunnett's multiple comparison correction, ${ }^{* *} p<0.05$

Since the contribution of BRG1 to alternative splicing regulation is unknown, we investigated whether this may contribute to the BRG1-dependent changes in gene expression. To do this, we performed a multivariate analysis of transcript splicing (MATS; [73-75]) of our entire RNA-seq datasets. After $72 \mathrm{~h}$ of BRG1 depletion, MATS pairwise comparison detected a genome wide total of 13 and 11 skipped exons, and 14 and 9 retained introns with si-SMARCA4-1 and si-SMARCA4-2, respectively
(Additional file 1: Figure 1C). At $144 \mathrm{~h}$ post BRG1 knockdown, this increased to 240 and 260 skipped exons, and 27 and 26 retained introns with si-SMARCA4-1 and siSMARCA4-2, respectively (Additional file 1: Figure 1D). Given the relatively large number of intron-exon junctions within the total LNCaP transcriptome, we conclude that BRG1 does not extensively contribute to alternative splicing as the mechanism for alterations in gene expression. However, we do note that at $144 \mathrm{~h}$ post-knockdown, 


\begin{abstract}
(See figure on next page.)
Fig. 2 Loss of BRG1 results in a down-regulation of gene expression. a Schematic of temporal BRG1 knockdown model used for RNA-seq. Samples were collected at 72hrs (si-NT control, si-SMARCA4-1 and si-SMARCA4-2) and 144hrs (si-NT, si-SMARCA4-1 and si-SMARCA4-2) post-siRNA transfection in duplicate for each condition at each time point $(\mathrm{n}=2$ ). Cells were transfected with either control siRNA (si-NT) or SMARCA4 siRNA. b SMARCA4 gene expression in control and post BRG1 depletion in the RNA-seq data, shown as transcripts per million reads (TPM). Control siRNA for 72 and $144 \mathrm{~h}$ is shown collectively as si-NT. SMARCA4 expression is significantly down-regulated at both time points, ${ }^{* * *} p<0.0001$. Bars denote mean, and error bars are SD. c Representative Western blots of BRG1 and GAPDH protein levels at 72 and $144 \mathrm{~h}$ post-transfection. $\mathbf{d}$ Adjusted relative density for BRG1 is calculated relative to GAPDH and normalised to the non-targeting control. Points denote mean, and error bars are SD. e, f Volcano plots of differentially expressed genes at $72 \mathrm{~h}$ and $144 \mathrm{~h}$ post-knockdown. Significantly down-regulated genes are blue and significantly up-regulated genes for 72 and $144 \mathrm{~h}$ post-knockdown are shown in orange and red, respectively. SMARCA4 differential expression is highlighted in purple. Expression is shown as normalised log2 counts per million reads. $\mathbf{g}$ Heatmap illustrating RNA-seq differential gene expression data for up $(n=16)$ and down $(n=126)$ regulated genes common to both time points after BRG1 depletion. Expression is represented as the normalised row Z-score of TPM. $\mathbf{h}, \mathbf{i}$, j KLK2, VAV3 and PCAT-1 gene expression from the RNA-seq datasets shown as TPM. Bars denote mean, and error bars are SD
\end{abstract}

the MATS analysis identified retention of the first intron from the Kallikrein 3 gene, which encodes prostate specific antigen (PSA) (Additional file 1: Figure 1E). This splice variant has previously been reported in LNCaP cells and generates a unique protein from canonical PSA [76]. While PSA has a well-known link to prostate cancer, the function of its alternative splice variant remains unknown.

\section{BRG1 binding is associated with expression of prostate cancer associated genes}

We further examined our RNA-seq datasets to determine which genes showed a significant change in expression at $72 \mathrm{~h}$ that was maintained at $144 \mathrm{~h}$. Of the genes that were down-regulated at the $72 \mathrm{~h}$ time point, 126 genes (75\%) remained down-regulated at $144 \mathrm{~h}$. Similarly, of the up-regulated genes, 16 (67\%) remained up-regulated at the extended time point (Fig. 2g). Within the downregulated gene set, we note a number of genes that have previously been associated with increased proliferation in prostate cancer; these include kallikrein 2 (KLK2), long non-coding RNA prostate cancer associated transcript 1 (PCAT1), Vav guanine nucleotide exchange factor 3 (VAV3) [69, 77-84] (Fig. 2h-j). We also examined the panel of prostate cell lines [69] and confirmed that, on average there is elevated expression of these genes in both prostate cancer cells and transformed prostate cell lines compared to normal prostate cells (Additional file 2: Figure 2A). This suggests a role for BRG1 in maintaining the expression of genes associated with prostate cancer proliferation.

We next sought to further explore commonalities in the genes significantly up- or down- regulated at both time points. We used 'Enrichr' $[85,86]$ to determine which transcription factors had enriched binding at the promoters of these genes in existing ChIP-seq datasets. We discovered that the most significantly enriched datasets were for the AR and FOXA1 (Fig. 3a), both of which are important for prostate cancer growth [66, 67, 87-91].
To investigate the potential coordinated function of these transcription factors with BRG1, we compared the ChIP-seq signal of BRG1 [91], AR [87] and FOXA1 [87] at BRG1 genome-wide binding sites in LNCaP cells in basal cell culture conditions. We found the profiles separated into three clusters. Cluster 1 sites displayed strong AR and FOXA1 binding, cluster 2 had moderate AR and strong FOXA1, and cluster 3 had minimal to no signal for AR or FOXA1 (Fig. 3b). Notably we found binding of all three factors at the promoters of BRG1 regulated genes KLK2 and PCAT1, and binding of BRG1 and FOXA1 upstream of the internal 3-prime promoter of VAV3 (Fig. 3c).

To investigate the cooperative relationship between BRG1, AR and FOXA1 in regulating gene expression, we depleted BRG1 for $144 \mathrm{~h}$ and assessed the abundance of AR and FOXA1 recruited to chromatin using cellular fractionation followed by Western blotting. We found that while the majority of AR was unbound, the small fraction of chromatin bound AR was reduced following BRG1 knockdown (Fig. 3d). Additionally, we found that FOXA1 was considerably depleted from the chromatin after BRG1 loss. Our RNA-seq data, as well as total protein levels detected by Western blot, suggest that BRG1 does not significantly alter the overall expression of AR or FOXA1 (Fig. 3d and Additional file 2: Figure 2B-C). Together, suggesting that BRG1 is required for these transcription factors to be loaded onto the chromatin without affecting their overall abundance.

Previous research has shown that BRG1 interacts with AR and FOXA1 in hormone dependent cancers [66, $68,92,93]$. Therefore, we preformed co-immunoprecipitations (co-IP) to see if this interaction was present in our LNCaP model. We found a modest interaction between AR and BRG1 in the AR co-IP, but no interaction between BRG1 and FOXA1, suggesting that in the basal cell culture conditions used in our model these factors do not interact sufficiently to be detected by co-IP (Fig. 3e). However, given the overlap of the ChIP-seq 


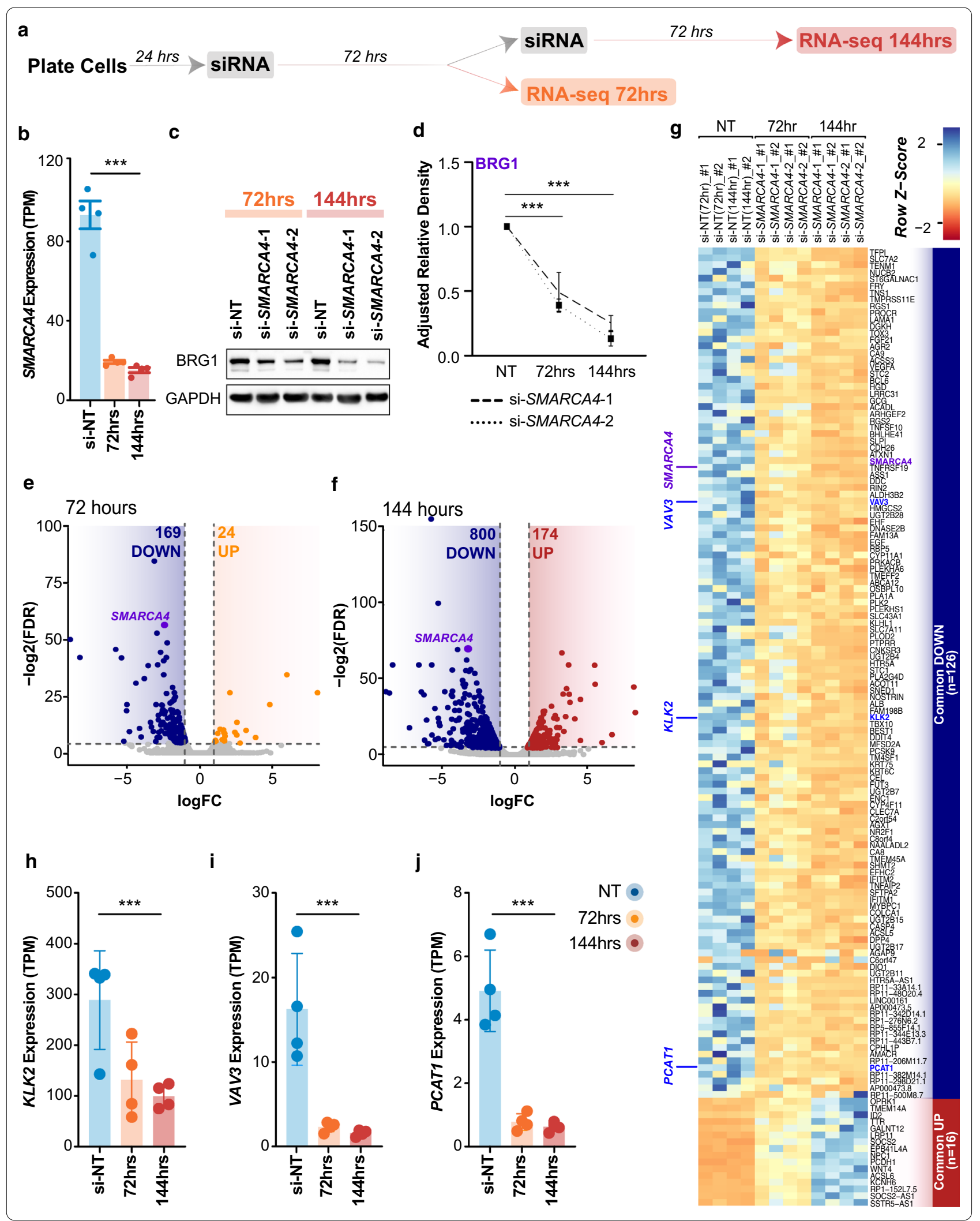




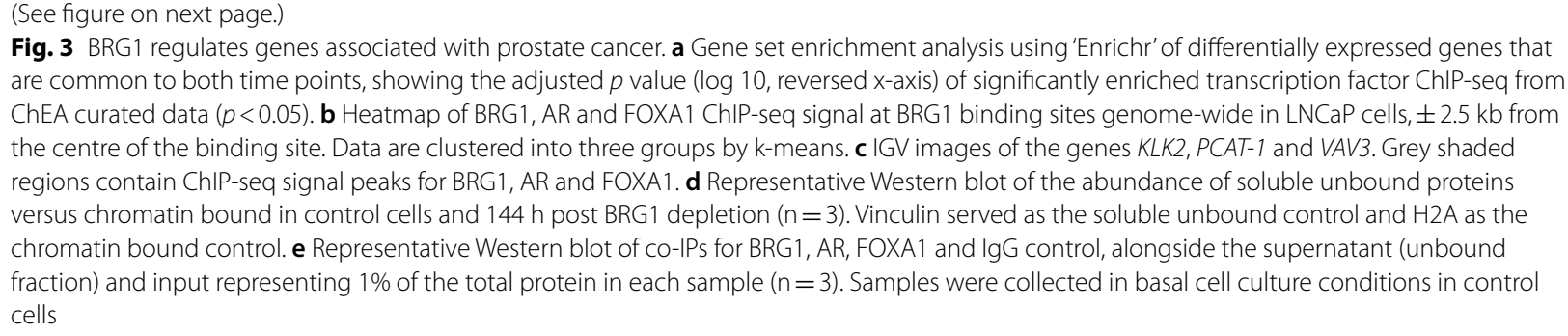

binding profiles and the fact that BRG1 depletion does not cause concomitant reduction in total AR and FOXA1, we hypothesise that there is either sequential binding of these factors or they are binding in close proximity without directly interacting.

\section{BRG1 binding is associated with the expression of DNA replication genes}

As the majority of significant gene changes occurred at $144 \mathrm{~h}$ post-knockdown, we next investigated the gene regulatory networks that were altered at this time point. Gene ontology analysis with Enrichr [85, 86] identified several significant $(\mathrm{FDR}<0.05) \mathrm{GO}$ terms pertaining to biological processes, cellular component and molecular function that were all broadly related to the cell cycle for down-regulated genes (Fig. 4a). However, there were no significant common processes related to the up-regulated genes. As BRG1 has previously been shown to interact with cell cycle master regulators, such as Rb and p53 [19, 94-96], we explored the relationship between the cell cycle and BRG1 further in our datasets. We compiled a list of 250 genes related to cell cycle processes, curated from the cell cycle GO terms, and of these examined the top 40 most significantly down-regulated genes in this list from our dataset. Of note among the list were several key genes involved in DNA replication initiation such as CDC6, CDT1 and CDC45, as well as the Minichromosome Maintenance (MCM) replicative helicase components MCM2 and MCM5 (Fig. 4b). To investigate if the effect on replication initiation gene expression was more widespread, we reviewed the gene expression of the other components in the MCM2-7 replicative helicase and the origin recognition complex (ORC) and found that several of these genes were also down-regulated (Fig. 4c, d). We confirmed the down-regulation of MCM5, CDC6 and ORC6 via Western blot, along with cell cycle regulator CHK1, which revealed almost undetectable expression by $144 \mathrm{~h}$ post BRG1 knockdown (Fig. 4e, f).

We investigated whether AR and FOXA1 were also colocalised with BRG1 at DNA replication genes. We examined the ChIP-seq binding profiles of AR, FOXA1 and BRG1 at the promoters of 91 DNA replication genes (determined from the DNA replication GO terms) that were expressed in LNCaP cells. We found that promoters of DNA replication genes containing the active histone marks H3K4me3 and H3K27ac also displayed a weak BRG1 ChIP-seq signal, but were completely absent of AR and FOXA1 ChIP-seq signal (Additional file 3: Figure 3A), for example at the promoters of CDC45, ORC6 (Additional file 3: Figure 3B). Additionally, we also note this pattern at a putative enhancer region within the $M C M 2$ gene (Additional file 3: Figure 3B). Our data suggest that BRG1 binding is associated with the expression of DNA replication genes in prostate cancer cells that is independent of AR and FOXA1.

\section{BRG1 depletion reduces proliferation}

Given BRG1 regulates several genes involved in proliferation and replication; we next asked if BRG1 depletion would alter cell cycle progression in LNCaP cells. We investigated this utilising the same siRNA-mediated approach to target BRG1 by depleting SMARCA4 and conducted flow cytometry cell cycle analysis at 72 and $144 \mathrm{~h}$ post-knockdown. We detected an increase of cells in $\mathrm{G} 1$ at $72 \mathrm{~h}$, which was enhanced by $144 \mathrm{~h}$. Specifically, at $144 \mathrm{~h}$ post BRG1 depletion there was $\sim 20 \%$ increase of cells in G1 and equivalent loss of cells in S phase (Fig. 5a, b). To confirm the increase in G1 population was indicative of a reduction in proliferation, we tracked the growth of LNCaP cells stably transformed with H2B-tagged mCherry using live cell imaging. We counted nuclei based on $\mathrm{H} 2 \mathrm{~B}-\mathrm{mCherry}$ fluorescence and found that the controls cells continued to proliferate across the entire time course which we extended to $216 \mathrm{~h}$ from the point of siRNA transfection (Fig. 5c). However, the growth of the BRG1 depleted cells began to slow from $\sim 48 \mathrm{~h}$ postknockdown and showed no increase in the number of nuclei from $72 \mathrm{~h}$ until the end of the time course (Fig. 5c). Moreover, Western blot of mitosis markers Cyclin A2 and phosphorylation of Serine10 on H3 was significantly reduced at $144 \mathrm{~h}$ post BRG1 depletion (Fig. $5 \mathrm{~d}$, e).

We investigated putative mechanisms underlying reduced proliferation in BRG1 depleted cells. Western blots of senescence regulators p21 and p16 showed no 
a

AR 21915096 ChIP-Seq LNCaP-1F5 Human BACH1 22875853 ChIP-PCR HELA AND SCP4 Human FOXA1 25552417 ChIP-Seq VCAP Human ZNF217 24962896 ChIP-Seq MCF-7 Human FOXM1 26456572 ChIP-Seq MCF-7 Human AR 22383394 ChIP-Seq PROSTATE CANCER Human FOXA1 21915096 ChIP-Seq LNCaP-1F5 Human SOX2 20726797 ChIP-Seq SW620 Human HNF4A 19822575 ChIP-Seq HepG2 Human ESR1 17901129 ChIP-ChIP LIVER Mouse $\begin{array}{lccccc}10^{0} & 10^{-1} & \begin{array}{c}10^{-2} \\ \text { adj. p-value }(\log 10)\end{array} & 10^{-3} & 10^{-4} \\ & & & \end{array}$

C

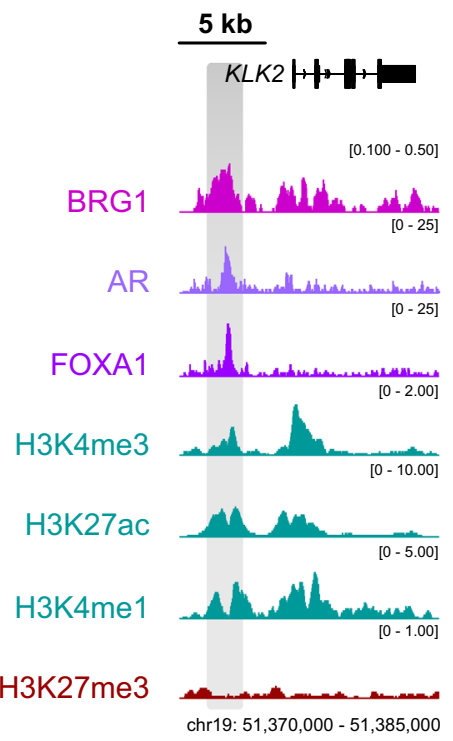

d

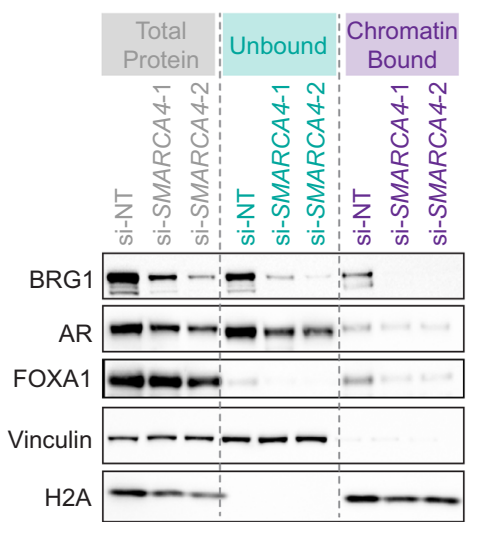

b

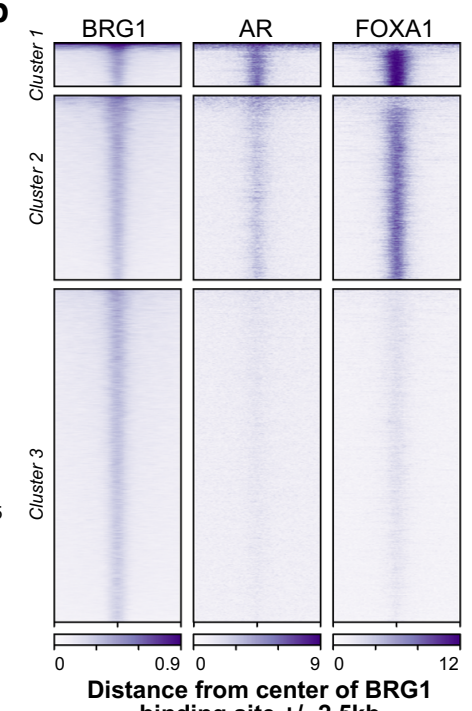
binding site $+/-2.5 \mathrm{~kb}$

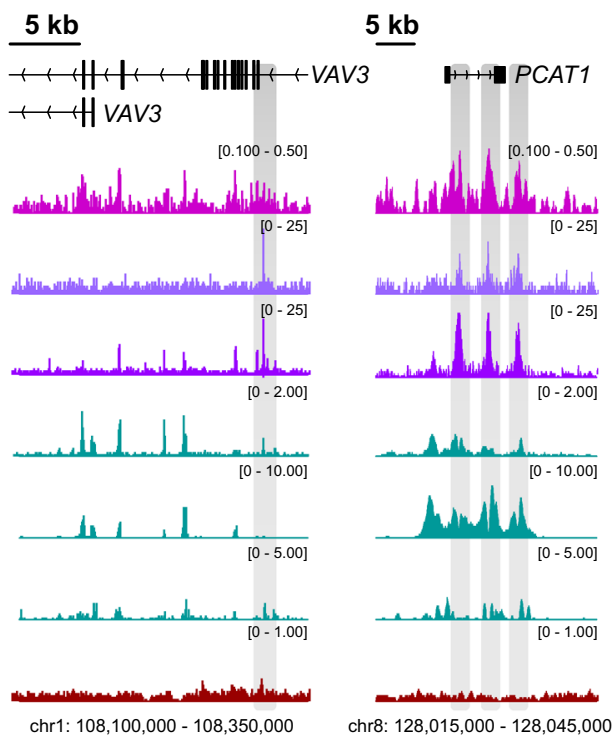

e

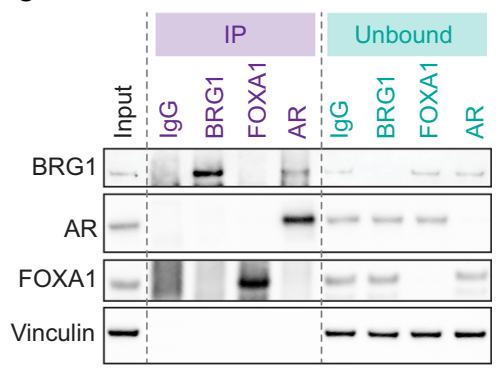




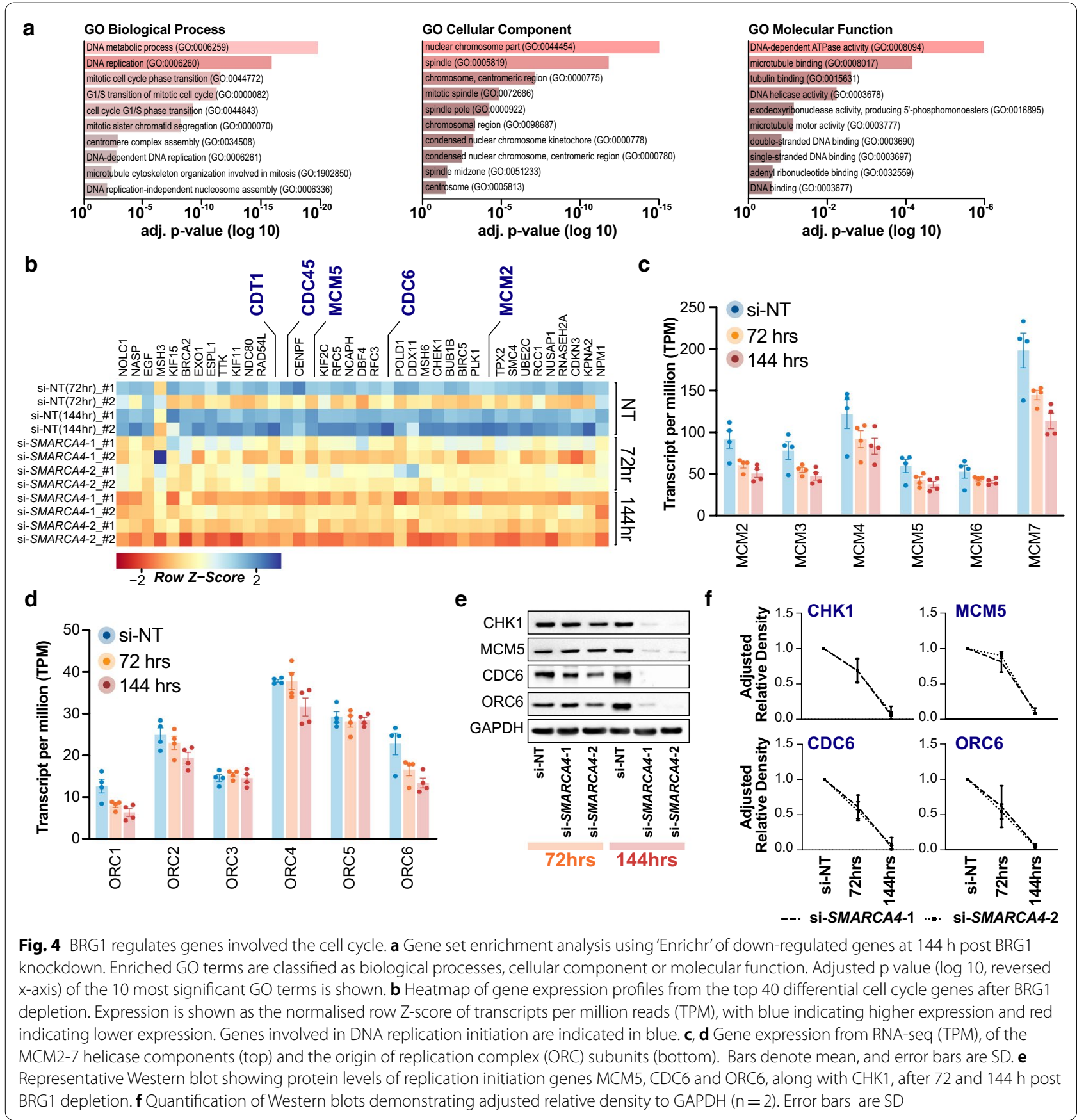

increase at $144 \mathrm{~h}$ post BRG1 knockdown, indicating that senescence was not activated (Fig. 5f). We also monitored the activity of caspase 3 in live fluorescence imaging as an apoptosis readout. LNCaP cells were monitored for $24 \mathrm{~h}$ before treatment with a combination of $50 \mu \mathrm{g} /$ $\mathrm{ml}$ of tumour necrosis factor- $\alpha$ (TNF $\alpha)$ and $100 \mathrm{nM}$ of SM164 to induce apoptosis, or $2 \mu \mathrm{M}$ of the DNA polymerase inhibitor aphidicolin to induce S-phase arrest. As expected, TNF $\alpha$ and SM164 induced apoptosis within
$24 \mathrm{~h}$ (Additional file 4: Figure 4A). Apoptosis was also observed in untreated or control siRNA transfected cells starting at four days in culture (Fig. 5g, Additional file 4: Figure 4A). However, aphidicolin treatment or BRG1 depletion suppressed the delayed apoptosis (Fig. 5g, Additional file 4: Figure 4A). Our RNA-seq data demonstrate that BRG1 depleted cells maintain caspase 3, caspase 8 and caspase 9 expression (Additional file 4: Figure 4B), indicative of an intact apoptosis pathway. The 


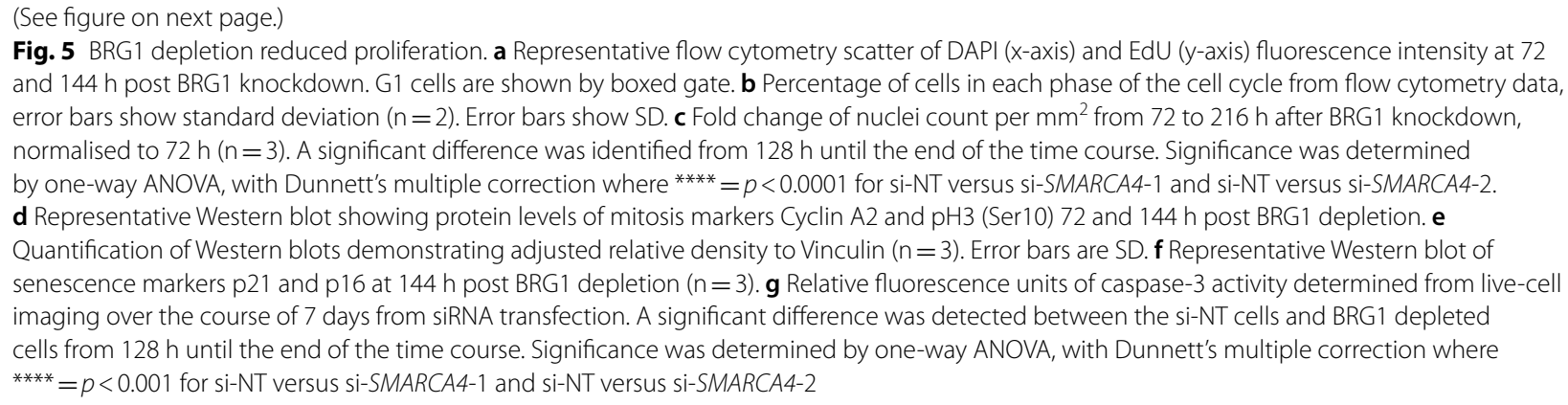

most likely interpretation of these data is that culture crowding in untreated or control siRNA cells becomes lethal, and that slowing proliferation with BRG1 depletion or aphidicolin rescues apoptosis induction. Therefore, neither apoptosis nor senescence was responsible for reduced proliferation in BRG1 depleted cells. We anticipate the observed reduction in proliferation stems from a failure to initiate replication, consistent with down-regulated CDC6, ORC5 and MCM proteins.

\section{Discussion}

Here, we examined the involvement of the SWI/SNF chromatin remodeller BRG1 and its associated encoding gene SMARCA4 in prostate cancer transcriptional deregulation. We found that over expression of SMARCA4 commonly occurs in both the TCGA prostate cancer cohort, irrespective of tumour subtype, and in a panel of prostate cancer cell lines. We also found that knockdown of the SMARCA4 gene, and consequently the BRG1 protein, results in down-regulation of pro-proliferative transcriptional pathways. These included genes already known to promote prostate cancer proliferation, as well as cell cycle and DNA replication genes. Reduction of gene expression in these pathways was concomitant with G1 arrest. Taken together, our results provide new insights into BRG1's contribution to transcriptional patterns relating to proliferation in prostate cancer.

We have demonstrated that SMARCA4 mRNA over expression is a universal feature of prostate cancer. Clinical datasets have shown that BRG1 protein levels are over-expressed in prostate cancer, in the absence of consistent significant deleterious genetic mutations evident in SMARCA4 [42, 44-46]. Using the large prostate cancer cohort from TCGA [50], we found that SMARCA4 was significantly over-expressed. Consistent with this, SMARCA4 expression was increased in a panel of both prostate cancer and transformed cell lines. These data emphasise that the overall increased expression of SMARCA4 is a characteristic of prostate cancer, irrespective of subtype.
BRG1 depletion followed by RNA-seq revealed multiple transcriptomic alterations that were regulated by BRG1 and related to proliferation. BRG1 depletion primarily resulted in the down-regulation of BRG1's target genes, indicating that the main role of BRG1 is to promote active gene expression. Within the down-regulated genes were genes associated with increased proliferation in prostate cancer including KLK2, PCAT-1 and VAV3. KLK2 is a known activator of PSA, which is an important biomarker of prostate cancer, and associated with decreased apoptosis $[77,84]$. PCAT-1 promotes proliferation through the oncoprotein Myc $[69,81]$, while VAV3 regulates AR activity to stimulate growth in prostate cancer [78-80, 82]. Both PCAT-1 and VAV3 are correlated with disease progression. Through an analysis of gene ontologies, we also found several cell cycle gene pathways were down-regulated with BRG1 depletion. This included numerous genes involved in DNA replication, which were among the most significantly down-regulated genes following BRG1 depletion. BRG1 is known to have a role in driving self-renewal and malignancy in B-cell acute lymphoblastic and acute myeloid leukaemias, cancers which also have over expressed BRG1 [22, 24]. Specifically, these leukaemias require high levels of BRG1 for de-condensation of the cell-specific $M Y C$ enhancer. In these cancers, a loss of BRG1 causes a reduction of enhancer-promoter interactions, reduced transcription factor occupancy and DNA looping which in turn reduces $M Y C$ expression [24]. This implies that the overexpression of BRG1 contributes to driving oncogenic transcriptional programmes which influence the proliferation capacity of cancer cells.

Our data revealed that BRG1 co-regulates the promoters of proliferation associated genes (KLK2, PCAT-1 and $V A V 3$ ) along with AR and FOXA1, and that these genes become down-regulated across our experimental time course of BRG1 depletion. Co-regulation of transcription by AR and FOXA1 in prostate cancer is associated with reprogrammed binding of $A R$ and oncogenic patterns of gene expression that are essential for AR-driven 


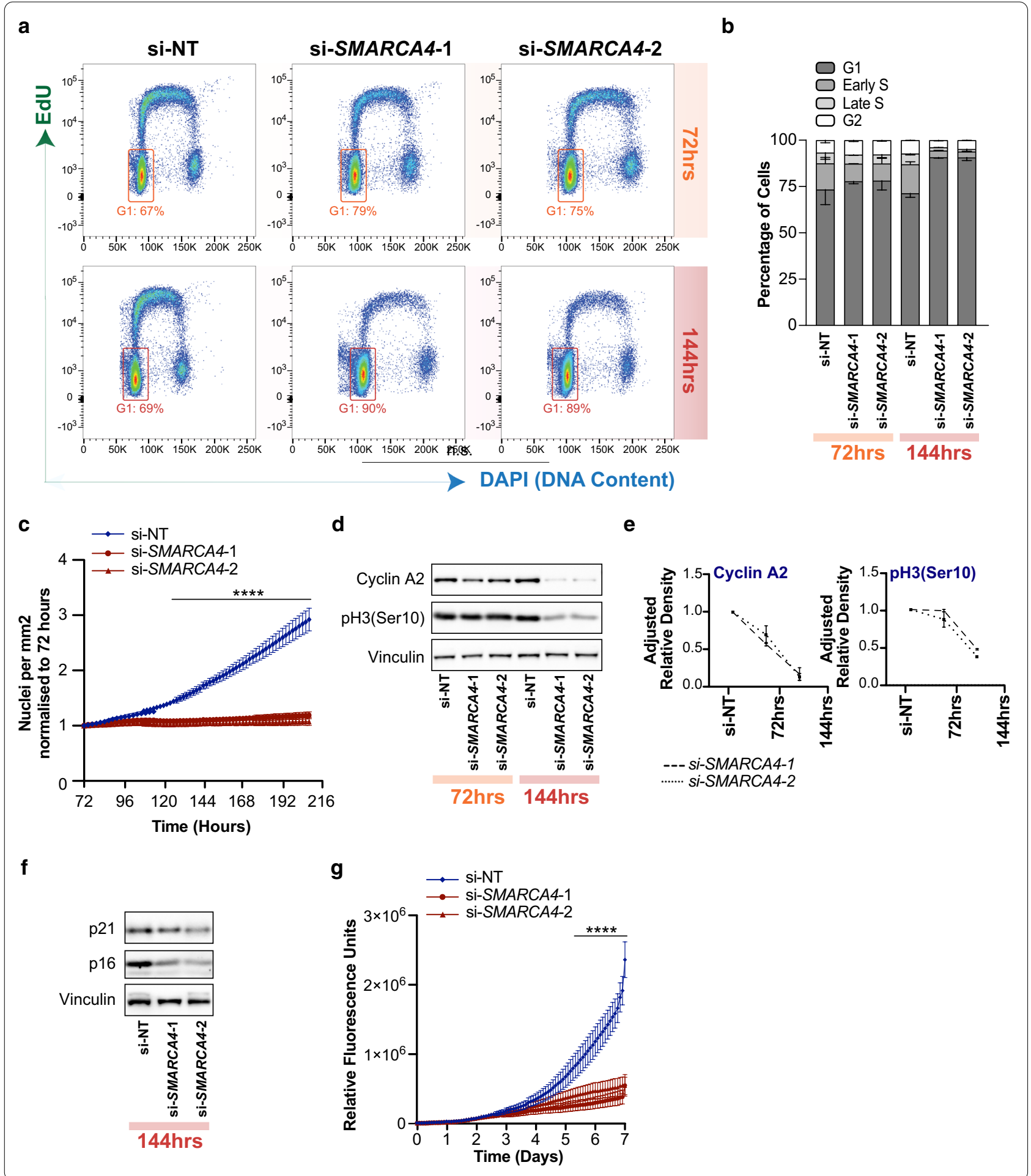

proliferation [92, 97]. Additionally, there is a high overlap of these reprogrammed AR binding sites between LNCaP cells and primary prostate tumour tissue [97]. Here, we have shown BRG1 gene regulation overlaps with these transcription factors at gene promoters, which is concomitant with expression of prostate cancer associated genes. We also demonstrated that depletion of BRG1 affects the level of chromatin binding for both AR 
and FOXA1. However, we did not find significant direct interaction by co-IP. This differs from direct interactions between these proteins observed others in previous works $[66,68,92,93]$ likely due to different experimental approaches. For example, we have investigated BRG1 interactions in basal cell culture conditions, while for example, Stelloo et al. [92] looked at AR interactions in the presence of synthetic androgens.

It is noteworthy that BRG1 depletion altered the expression of DNA replication genes through a mechanism that appears independent of AR and FOXA1, suggesting that BRG1 has additional roles in other gene regulatory networks. As BRG1 is known to regulate cell cycle genes in other cancers, such as in leukaemia [24] and breast cancer [98], we speculate it is possible that regulation of cell cycle and DNA replication genes may be a general feature of BRG1 over expression in cancer, while genes co-regulated by BRG1, AR and FOXA1 are important in a prostate cancer context.

\section{Conclusions}

In summary, our data identify fundamental role for BRG1 in maintaining active transcription for proliferation of prostate cancer cells. We find that BRG1 promotes gene expression in prostate cancer models with varying degrees of dependence on AR and FOXA1. BRG1 is required to drive the expression of numerous prostate cancer specific genes in an AR/FOXA1 dependant manner, but also works independently to drive the expression of pro-proliferative and DNA replication genes. These results provide important functional information regarding the role of BRG1 controlling proliferation in prostate cancer cells.

\section{Materials and methods \\ Cell culture and siRNA transfection}

Normal prostate epithelial cells (PrEC) (Cambrex Bio Science, CC-2555) were cultured in PrEBM (Clonetics, CC-3165) according to the manufacturer's protocol. Briefly, PrEC cells were seeded at 2500 cells per $\mathrm{cm}^{2}$ and medium was replaced every two days. Cells were passaged at approximately $80 \%$ confluence. To passage a T75 flask, PrEC cells were rinsed in $6 \mathrm{ml}$ Hanks balanced salt solution (Thermo Fisher Scientific, 14025076) then detached with $2 \mathrm{ml}$ pre-warmed $0.025 \%$ trypsin-EDTA and incubated at room temperature for $5 \mathrm{~min}$. Trypsin was inactivated with $12 \mathrm{ml}$ of trypsinneutralising solution (Clonetics, CC-5002), and cells were centrifuged at $300 \times g$ for $5 \mathrm{~min}$. The supernatant was aspirated, and the cell pellet was re-suspended in PrEBM. The number of cells was determined on the Countess automated counter and was re-seeded at the appropriate density based on experimental needs. Cells were discarded after $\sim 16$ population doublings.

PC3 cells (ATCC, CRL-1435) were maintained in RPMI medium (Gibco, 11875-093) with 10\% FBS, $11 \mathrm{ml}$ of $1 \mathrm{M}$ HEPES (Gibco, 15630080) and Pen/Strep. LNCaP cells (ATCC, CRL-1740) were cultured using custom T-Medium from Gibco (DMEM low glucose (GIBCO, 31600-034), Kaighn's modified F-12 medium (F-12 K, 211227-014), insulin $500 \times$ bovine pancreas (Sigma I1882), T3 $6.825 \mathrm{ng} / \mathrm{ml}$ Tri-iodothyronine (Sigma-Aldrich, T5516), Transferrin 500× (SigmaAldrich, T5391), Biotin 500× (Sigma-Aldrich, B4639), Adenine $500 \times$ (Sigma-Aldrich, A3259)). Both prostate cell lines were cultured under recommend conditions; $37{ }^{\circ} \mathrm{C}$ with $5 \% \mathrm{CO}_{2}$. When the cells reached $\sim 80 \%$ confluence they were passaged or seeded as per experimental requirements. For siRNA transfection, LNCaP cells were seeded into 6-well plates at a density of $2.5 \times 10^{5}$ cells per well or $10 \mathrm{~cm}$ dishes at $1.5 \times 10^{6}$ cells per dish. The cells were transfected with either on target SMARCA4 siRNA (Horizon, J-010431-06-0005 [siSMARCA4-1] or J-010431-07-0005 [si-SMARCA4-2]) or the non-targeting control siRNA pool (Horizon, D-001810-10-05 [si-NT]) $24 \mathrm{~h}$ after seeding the cells using DharmaFECT 2 (Thermo Scientific, T-2002-03) as per the manufacturer's instructions. To maintain the knockdown over a 6 -day period, at $72 \mathrm{~h}$ post-transfection the cells were harvested, split at a ratio of 1:2 into two new wells and reverse-transfected with siRNA. The cells were then incubated for a further $72 \mathrm{~h}$ before collection.

\section{Viral transduction and selection of H2B-mCherry LNCaP cells}

Replication incompetent lentiviral particles were produced by transfecting the pLXSN-H2B-mCherry plasmid (kindly provided by A. J. Cesare) into Phoenix cells and collecting the supernatant after $48 \mathrm{~h}$. LNCaP cells were seeded into 6-well plates in antibiotic free media at $2 \times 10^{5}$ cells per well. After $24 \mathrm{hrs}, 2 \mathrm{~mL}$ of viral supernatant, mixed with fresh media at 1:1 ratio, was added to the cells. This was replaced with fresh media after $24 \mathrm{~h}$ and the cells were allowed to recover for a further $24 \mathrm{~h}$ before checking for the presence of mCherry fluorescence. mCherry positive cells were selected for with $600 \mu \mathrm{g} / \mathrm{ml}$ of G418 (Sigma-Aldrich, A1720). Cells were monitored for cell death and media replaced and cells passaged as necessary. After 7 days, G418 was reduced to $50 \%$; the cells were maintained in G418 for live cell imaging experiments. 


\section{Growth assay}

siRNA knockdown was performed as described for $\mathrm{LNCaP}$ cells containing the stable expression of mCherry-H2B fusion protein. At the point of siRNA transfection, the cells were placed in the Incucyte live cell imaging system (Sartorius). Images were taken every $2 \mathrm{~h}$ for $216 \mathrm{~h}$ with 16 images captured per well of a 6-well plate. The mean score each of the 16 photos per well was reported as the number or nuclei per $\mathrm{mm}^{2}$. Relative fold change was calculated by the difference between $0 \mathrm{~h}$ and each two-hour window up to $72 \mathrm{~h}$ and then after reseeding the cells between $72 \mathrm{~h}$ and each two-hour window until the end pf the time course. A significant change was calculated by one-way ANOVA, with each BRG1 on-target siRNA compared to the non-targeting control. The results were corrected for multiple comparisons with Dunnett's test. A significant change is defined as $* * * * * 0<0.0001$

\section{Caspase- 3 apoptosis assay}

LNCaP cells were seeded in a 96-well plate at 4000 cells per well, with up to 8 technical replicates per condition. After 24hrs, all cells were treated with NucView Caspase-3 Enzyme Substrate 488 (Biotium, 10402), and appropriate wells also treated with siRNA as described above, then placed in the Incucyte live cell imaging system (Sartorius). One image per well was taken every $2 \mathrm{~h}$ for 7 days. After $24 \mathrm{~h}$ in the Incucyte, the positive control cells were treated with either $50 \mu \mathrm{g} / \mathrm{ml}$ of TNF $\alpha$ (Sigma-Aldrich, H8916) + $100 \mathrm{nM}$ of SM164 (Selleckchem, S7089), or $2 \mu \mathrm{M}$ of Aphidicolin (Sigma-Aldrich, A0781). Integrated fluorescence intensity was calculated within the Incucyte Zoom software using the summed pixel intensity in calibrated units (CU) to determine the relative fluorescence units per image with the follow equation; $C U \times \mu \mathrm{m}^{2}$ /image. A significant change was calculated by one-way ANOVA, with each BRG1 on-target siRNA compared to the non-targeting control. The results were corrected for multiple comparisons with Dunnett's test. A significant change is defined as ***** $p<0.0001$.

\section{Quantitative real-time PCR (qRT-PCR)}

RNA was extracted with TRIzol reagent (Thermo Scientific, 15596026), according to the manufacturer's protocol. Extracted RNA was re-suspended in $30 \mu \mathrm{l}$ of nuclease-free water and quantified on the NanoDrop spectrophotometer (Thermo Scientific). cDNA synthesis was carried out with 500 ng of RNA using the SensiFAST cDNA Synthesis Kit (Bioline, BIO-65054) according to the manufacturer's instructions.

qRT-PCR was carried out on the CFX384 Touch RealTime PCR Detection System (Bio-Rad). A master mix was made for each qRT-PCR target containing $5 \mu \mathrm{l}$ of KAPA Universal SYBR Fast PCR mix (KAPA Biosystems, KK4602), $0.6 \mu \mathrm{l}$ of $5 \mu \mathrm{M}$ forward primer, $0.6 \mu \mathrm{l}$ of $5 \mu \mathrm{M}$ reverse primer and $1.8 \mu \mathrm{l}$ of nuclease-free water per reaction. Reactions conditions were $95{ }^{\circ} \mathrm{C}$ for $3 \mathrm{~min}$, followed by $45 \times$ cycles of $95{ }^{\circ} \mathrm{C}$ for $3 \mathrm{~s}$ and $60{ }^{\circ} \mathrm{C}$ for $30 \mathrm{~s}$, then a melt curve analysis $\left(65-95^{\circ} \mathrm{C}\right.$, increasing at a rate of $0.5{ }^{\circ} \mathrm{C}$ every $5 \mathrm{~s}$ ). Primers to detect $S M A R C A 4$ were CAGAACGCACAGACCTTCAA (forward) and TCA CTCTCCTCGCCTTCACT (reverse) and for detection of $18 S$ GGGACTTAATCAACGCAAGC (forward) and GCAATTATTCCCCATGAACG (reverse). Relative gene expression was calculated using $\mathrm{ddCt}$ and normalised to $18 S$. A significant change in gene expression of SMARCA4 between PrEC, LNCaP and PC3 cells was determined by one-way ANOVA and corrected with Tukey's test for multiple comparisons.

\section{Western blot}

Whole-cell lysates were collected with lysis buffer (50 mM HEPES, $150 \mathrm{mM} \mathrm{NaCl,} \mathrm{10 \%} \mathrm{Glycerol,} \mathrm{1 \%}$ Triton-X-100, $1.5 \mathrm{mM} \mathrm{MgCl}_{2}, 1 \mathrm{mM}$ EGTA, $10 \mathrm{mM}$ Pyrophosphate, $100 \mathrm{mM} \mathrm{NaF}$, Roche protease inhibitor cocktail $1 \times$ ), and protein level quantified using the Pierce BCA Assay Kit (Thermo Scientific, 23227) according to the manufacturer's instructions. Sample reducing agent (Thermo Scientific, NP0004), loading buffer (Thermo Scientific, NP0007) and $10 \mu \mathrm{g}$ protein were combined with water to a final volume of $25 \mu \mathrm{l}$. Protein samples were heated at $90{ }^{\circ} \mathrm{C}$ for 5 min then allowed to cool to room temperature. Protein samples were loaded on a NuPage Novex Bis-Tris $4-12 \%$ gel (Thermo Scientific, NP0321BOX) and electrophoresed at $100 \mathrm{~V}$ for $1.5 \mathrm{~h}$ in a $1 \times$ MOPS buffer $(50 \mathrm{mM}$ MOPS (Biochemicals Astral Scientific, BIOMB03600, $50 \mathrm{mM}$ Tris base, 0.1\% SDS, $1 \mathrm{mM}$ EDTA [pH 7.7]). Proteins were transferred to a polyvinylidene fluoride membrane (Bio-Rad, $1620177)$ at $30 \mathrm{~V}$ for $1 \mathrm{~h}$ using $1 \times$ transfer buffer $(25 \mathrm{mM}$ Tris base, $192 \mathrm{mM}$ Glycine [pH 8.3]) with $10 \%$ methanol (Sigma-Aldrich, 322415). Membranes were blocked for $1 \mathrm{~h}$ with $5 \%$ skim milk in TBS-T (20 mM Tris, $150 \mathrm{mM}$ $\mathrm{NaCl}, 0.1 \%$ Tween 20 [pH 7.6]) at $4{ }^{\circ} \mathrm{C}$. Primary antibodies used were BRG1 (Santa Cruz, sc-10768X), GAPDH (Ambion, AM4300), CHK1 (CST, 2360S), ORC6 (CST, 4737S), CDC6 (CST, 3387S), MCM5 (abcam, ab17967), AR (CST, D6F11), FOXA1 (CST, E7E8W), Vinculin (Sigma-Aldrich, V9131), H2A (CST, 12349S), p21 (CST, 2947S), p16 (CST, 92803S), Cyclin A2 (Abcam, ab181591) and $\mathrm{pH} 3($ Ser10) (CAT, 3377S). Primary antibodies were incubated on samples overnight at $4{ }^{\circ} \mathrm{C}$ with rotation. The membrane was then washed three times for $10 \mathrm{mins}$ each in TBS-T with rotation. Secondary antibodies goat antimouse (Santa Cruz, sc-2005) and goat anti-rabbit (Santa 
Cruz, sc-2004) were diluted in TBS-T containing 5\% skim milk and incubated at $4{ }^{\circ} \mathrm{C}$ with rotation for $1 \mathrm{~h}$. The membrane was washed three times for $10 \mathrm{~min}$ in TBS-T. The membrane was then covered with ECL solution (Perkin Elmer, NEL104001EA), incubated for $1 \mathrm{~min}$ at room temperature, and visualised by X-ray film or digitally imaged on the Bio-Rad ChemiDoc MP Imaging System (Bio-Rad). Adjusted relative density calculations were processed through ImageJ $[99,100]$.

\section{Chromatin fractionation}

LNCaP cells were treated with siRNA as described above for $144 \mathrm{~h}$. Cells were collected and resuspended in CSK buffer (10 mM Hepes-KOH [pH7.4], $100 \mathrm{mM} \mathrm{NaCl}$, $3 \mathrm{mM} \mathrm{MgCl}^{2}$ and $0.5 \%$ Triton-X-100, freshly supplemented with $1 \mathrm{mM}$ DTT and $1 \times$ protease inhibitor cocktail). Cell suspensions were incubated for $5 \mathrm{~min}$ on ice and then centrifuged at $1500 \times g$ for $4 \mathrm{~min}$ at $4{ }^{\circ} \mathrm{C}$. Supernatants containing the cytoplasmic and nuclear unbound soluble proteins were transferred to a fresh tube and frozen at $-80^{\circ} \mathrm{C}$. The pellet containing the chromatin bound proteins was washed in CSK buffer minus Triton$\mathrm{X}-100$. The pellet was then resuspended in CSK buffer. The pellet was then resuspended in CSK buffer with $0.1 \%$ triton-X-100 and chromatin bound proteins release through sonication with two rounds of 10 cycles $(30 \mathrm{~s}$ on, $30 \mathrm{~s}$ off) in the Biorupter. Fractions were validated with Western blot of Vinculin (soluble/unbound) and H2A (chromatin bound).

\section{Co-immunoprecipitation (co-IP)}

LNCaP cells were lysed with $0.5 \mathrm{ml}$ of non-denaturing lysis buffer (20 mM Tris- $\mathrm{HCl}$ [pH 8.0], $137 \mathrm{mM} \mathrm{NaCl}$, 1\% IGE-PAL, 2 mM EDTA, 1:100 Benzonase), plus 1:10 phosSTOP/PIC on ice for $10 \mathrm{~min}$. The cell suspension was mechanically dissociated by drawing it through a $27 \mathrm{G}$ syringe to break apart the nuclei. Cell lysates were then centrifuged at $13,000 \times g$ for $15 \mathrm{~min}$ at $4{ }^{\circ} \mathrm{C}$ to pellet debris. The supernatant was transferred to a new tube and quantified with the BCA assay (Thermo Fisher, 23225). Protein A/G beads (Thermo Fisher, 88802) were washed three times in lysis buffer; then, protein lysates were then pre-cleared with $20 \mu \mathrm{l}$ of the washed beads for $30 \mathrm{~min}$ at $4{ }^{\circ} \mathrm{C}$. Protein lysates were then transferred to a new tube, and $0.5 \mathrm{~g}$ of appropriate antibody was added to each lysate (BRG1, Santa Cruz, sc-10768X; AR, CST, D6F11; FOXA1 CST, E7E8W, Mouse IgG isotype control, Thermo Fisher, 31903), and incubated for $2 \mathrm{~h}$ at $4{ }^{\circ} \mathrm{C}$. Following this, $50 \mu \mathrm{l}$ of prewashed A/G beads was combined with each sample and incubated for a further $30 \mathrm{~min}$ at $4{ }^{\circ} \mathrm{C}$ with shaking. The protein-antibody-bead complexes were then washed three times in cold non-denaturing lysis buffer. Proteins were then eluted in $40 \mu \mathrm{l}$ of $2 \times$ LDS buffer and frozen at $-20{ }^{\circ} \mathrm{C}$. Detection of proteins that immunoprecipitated with the target was performed by Western blot, which was run with the input which represents $1 \%$ of the total protein in the co-IP.

\section{Flow cytometric cell cycle analysis}

LNCaP cells were seeded at $1.5 \times 10^{6}$ cells per $10 \mathrm{~cm}$ dish and transfected with siRNA as described. At 72 and $144 \mathrm{~h}$ post-transfection, the cells were treated with $10 \mu \mathrm{M}$ EdU (Sigma-Aldrich, 900584) for $30 \mathrm{~min}$. Remaining EdU was washed off the cells with PBS before harvesting cells, and then, $1 \times 10^{6}$ cells were fixed in $70 \%$ ethanol and frozen at $-20^{\circ} \mathrm{C}$. Cells were then diluted 1 in 4 with PBS then pelleted and re-suspended in $1 \mathrm{ml}$ of PBS containing 1\% BSA (Sigma-Aldrich, A2058). Cells were again pelleted, resuspended in $500 \mu \mathrm{l}$ of click reaction mix ( $10 \mu \mathrm{M}$ carboxyfluorescein TEG-azide, $10 \mathrm{mM}$ Sodium L-ascorbate and $2 \mathrm{mM}$ Copper-II-sulphate diluted in PBS), and incubated in the dark at room temperature for $30 \mathrm{~min}$. Samples were then diluted with $5 \mathrm{ml}$ of PBS containing 1\% BSA and $0.1 \%$ Tween-20. Cells were again pelleted, washed with PBS and then resuspended in $500 \mu \mathrm{l}$ of PBS containing $1 \%$ BSA, $0.1 \mathrm{mg} / \mathrm{ml}$ of RNase and $1 \mu \mathrm{g} / \mathrm{ml}$ of DAPI. Samples were analysed on the Canto II (BD Biosciences). Forward and side scatter were used to select a population of cells free of cell debris and doublets. Cells were analysed using B450 (FTIC - EdU positive) and B510 (DAPI) lasers. 50,000 single-cell events were recorded for each ample. FlowJo software v10.5 was used to analyse the data. Data were collected in biological triplicate.

\section{RNA-seq experiments}

Total RNA was extracted with TRIzol reagent (Thermo Fisher, 15596026), quantified on the Qubit and quality assessed with the Bioanalyzer. An aliquot of $500 \mathrm{ng}$ of total RNA was spiked with external controls ERCC RNA spike-in Mix (Thermo Scientific, 4456740) and libraries constructed with the TruSeq Stranded mRNA sample preparation kit (Illumina, 20020594) according to the manufacturer's protocol. mRNA Libraries were quantified on Qubit and then stored at $-20{ }^{\circ} \mathrm{C}$. Library quality and fragment size of RNA-seq libraries were assessed on the Bioanalyzer, and then, KAPA Library Quantification (KAPA Biosystems, KK4824) was performed according to the manufacturer's protocol. The KAPA quantification results were used to dilute the libraries to $2 \mathrm{nM}$ for sequencing. RNA-seq samples were sequenced for 100 cycles of paired-end reads on the Illumina HiSeq 2500 platform, with four samples multiplexed per lane of the high output run. 


\section{RNA-seq data analysis}

RNA-seq data were processed as described in Taberlay \& Achinger-Kawecka et al. [9). Briefly, read counts were normalised with ERCC spike in controls, mapped to hg19/GRCh37 using STAR and counted into genes using the featureCounts [101] programme. GENCODE v19 was used as a reference transcriptome to determine the transcript per million read (TPM) value. Fold change was calculated within each time point as the $\log 2$ ratio of normalised reads per gene using the edgeR package in $R$. Genes with a fold change of \pm 1.5 and FDR $<0.01$ were considered significantly different. Volcano plots of differential expression were created in $\mathrm{R}$ with ggplots 2 and heatmaps with the heatmap 2 package with normalised row Z-score. PCA was performed in $\mathrm{R}$ using the edgeR package with log counts per million (logCPMS) over GENCODE v19 annotated gene coordinates and normalising the read counts to library size. RNA-seq multivariate analysis of transcript splicing (MATS) to calculate exon skipping and intron retention was performed with the MATS python package v4.0.2 [73-75]. Transcription factor and GO term enrichment was obtained from Enrichr (http://amp.pharm.mssm.edu/Enrichr/) online gene list analysis tool $[85,86]$.

\section{TCGA and prostate cell line expression analysis}

Pre-processed RNA-seq data from the TCGA prostate adenocarcinoma cohort were downloaded (cancergenome.nih.gov) for both normal and tumour samples. The average of tumour $(n=486)$ and normal $(n=52)$ samples was calculated to determine mean expression. Separation of tumours by Gleason score and molecular subtype was performed in $\mathrm{R}$ using the associated clinical data to subset the appropriate groups. Significance was calculated for tumour versus normal using an unpaired t test. For comparison between Gleason score or molecular subtype, significance was calculated using one-way ANOVA with Dunnett's multiple comparison correction.

Expression data for prostate cell lines from Presner et al. [69] were downloaded from http://www.betastasis .com/prostate_cancer/. Significance between normal, cancer and transformed cell lines was calculated using one-way ANOVA with Dunnett's multiple comparison correction.

\section{ChIP-seq data}

The following LNCaP ChIP-seq data were obtained from GEO (ncbi.nlm.nih.gov/geo/); BRG1 accession GSE72690 [91], H3K4me3 and H3K27me3 accession GSE38685 [102], H3K27ac and H3K4me1 accession GSE73785 [9]. These data were processed through NGSane pipeline as previously described $[9,102]$. Pre-processed bigwig files for FOXA1 and AR were obtained from GEO accession GSE114274 [87]. Genome browser images of ChIP-seq data were taken from IGV. Heatmaps of ChIP-seq signal were created with deeptools [103].

\section{Supplementary Information}

The online version contains supplementary material available at https://doi. org/10.1186/s13148-021-01023-7.

Additional file 1. Figure 1. a SWI/SNF subunit gene expression (TPM) from RNA-seq data. All subunits, except SMARCA4 (shown in Fig. 2a), are not significantly altered. Bars denote mean, and error bars are SD. b PCA plot characterising the trend in expression profiles between the non-targeting control and after BRG1 knockdown. Each point on the plot represents an RNA-seq sample. Samples are separated by principal components 1 and 2, which together explain $58.37 \%$ of the variance between the samples. $\mathbf{c}$ Number of skipped exons at 72 hours and 144 hours after BRG1 knockdown with si-SMARCA4-1 (black) and si-SMARCA4-2 (grey). d Number of retained introns at 72 hours and 144 hours post BRG 1 depletion with si-SMARCA4-1 (black) and si-SMARCA4-2 (grey). e Sashimi plot of exons one and two of the KLK3 gene in the non-targeting and 144 hour knockdown RNA-seq data. Arcs represent the number of split reads across the exons. Lower numbers represent increased retention of the first intron after BRG1 knockdown.

Additional file 2. Figure 2. a Expression of KLK2, PCAT- 1 and VAV3 in prostate cell lines grouped as normal, cancer or transformed. b AR and FOXA1 gene expression from the RNA-seq datasets shown as TPM. Bars denote mean, and error bars are SD.

Additional file 3. Figure 3. a Heatmap of replication gene promoters, $+/-5 \mathrm{~kb}$ from the transcription start site. $\mathbf{b}$ IGV images of the genes CDC45, ORC6 and MCM2. Grey shaded regions contain ChIP-seq signal peaks for BRG1 and active histone modifications.

Additional file 4. Figure 4. a Relative fluorescence units of caspase-3 activity determined from live-cell imaging over the course of 7 days. Treatments were added 24 hours after initial imaging. b CASP3, CASP8 and CASP9 gene expression from the RNA-seq datasets shown as TPM. Bars denote mean, and error bars are SD.

\section{Abbreviations}

AR: Androgen receptor; BRG1: Brahma-related gene 1; FOXA1: Forkhead box A1; KLK2: Kallikrein 2; MCM: Minichromosome maintenance; ORC: Origin recognition complex; PCAT1: Prostate cancer associated transcript 1; PrEC: Prostate epithelial cells; PSA: Prostate specific antigen; MATS: Multivariate analysis of transcript splicing; Rb: Retinoblastoma protein; SMARCA4: SWI/SNFrelated, matrix-associated, actin-dependent regulator of chromatin, subfamily A, member 4; SWI/SNF: Switch/sucrose non-fermentable;TCGA: The cancer genome atlas; VAV3: Vav guanine nucleotide exchange factor 3.

\section{Acknowledgements}

We thank Suat Dervish and the Westmead Flow Cytometry facility for the FACS analysis infrastructure.

\section{Authors' contributions}

This study was initiated and designed by KAG, SJC and PCT. Experiments were performed by KAG, SGP, GRK and SR. Analysis and interpretation of next-generation data was performed by KAG, CMG, JAK and PL. Initial manuscript draft was written by KAG. Manuscript editing and reviewing was conducted by KAG, JAK, SGP, GRK, AJC, SJC and PCT. All authors have read and approval the final version of this manuscript. Funding for this work was provided by AJC, SJC and PCT. All authors read and approved the final manuscript.

\section{Funding}

This work is supported by grants awarded to A.J.C, S.J.C and P.C.T. A.J.C. is supported by grants from the NHMRC $(1162886,1185870)$, the Goodridge Foundation and the Neil and Norma Hill Foundation. S.J.C. is supported by grants 
$(1011447,1070418,1051757)$ and a fellowship (1156408) from the NHMRC. P.C.T. is supported by grants from the Cure Cancer Australia Foundation (1060713) and the NHMRC (1051757, 1161985), and a fellowship (1109696) and investigator grant from the NHMRC (1176417).

\section{Availability of data and materials}

The BRG1 knockdown RNA-seq data generated for this study is available from GEO, accession number GSE150252.

\section{Ethics approval and consent to participate}

Not applicable.

\section{Consent for publication}

Not applicable.

\section{Competing interests}

The authors declare that they have no competing interests.

\section{Author details}

${ }^{1}$ Epigenetics Laboratory, Genomics and Epigenetics Theme, Garvan Institute of Medical Research, Sydney, NSW 2010, Australia. ${ }^{2}$ Genome Integrity Unit, Children's Medical Research Institute, University of Sydney, Westmead, NSW 2145, Australia. ${ }^{3}$ Tasmanian School of Medicine, College of Health and Medicine, University of Tasmania, TAS, Hobart 7000, Australia. ${ }^{4}$ St Vincent's Clinical School, UNSW Sydney, Sydney, NSW 2000, Australia.

Received: 24 August 2020 Accepted: 4 February 2021

Published online: 17 February 2021

\section{References}

1. Giles KA, Taberlay PC. The role of nucleosomes in epigenetic gene regulation. In: Hesson LB, Pritchard AL, editors. Clinical epigenetics. Singapore: Springer; 2019. p. 87-117.

2. Taberlay PC, Statham AL, Kelly TK, Clark SJ, Jones PA. Reconfiguration of nucleosome-depleted regions at distal regulatory elements accompanies DNA methylation of enhancers and insulators in cancer. Genome Res. 2014;24(9):1421-32.

3. Thurman RE, Rynes E, Humbert R, Vierstra J, Maurano MT, Haugen $\mathrm{E}$, et al. The accessible chromatin landscape of the human genome. Nature. 2012;489(7414):75-82.

4. Heintzman ND, Stuart RK, Hon G, Fu Y, Ching CW, Hawkins RD, et al. Distinct and predictive chromatin signatures of transcriptional promoters and enhancers in the human genome. Nat Genet. 2007;39(3):311-8.

5. Skulte KA, Phan L, Clark SJ, Taberlay PC. Chromatin remodeler mutations in human cancers: epigenetic implications. Epigenomics. 2014;6(4):397-414.

6. Li XY, Thomas S, Sabo PJ, Eisen MB, Stamatoyannopoulos JA, Biggin MD. The role of chromatin accessibility in directing the widespread, overlapping patterns of Drosophila transcription factor binding. Genome Biol. 2011;12(4):R34.

7. Venkatesh S, Workman JL. Histone exchange, chromatin structure and the regulation of transcription. Nat Rev Mol Cell Biol. 2015;16(3):178-89.

8. Makova KD, Hardison RC. The effects of chromatin organization on variation in mutation rates in the genome. Nat Rev Genet. 2015;16(4):213-23.

9. Taberlay PC, Achinger-Kawecka J, Lun AT, Buske FA, Sabir K, Gould $\mathrm{CM}$, et al. Three-dimensional disorganization of the cancer genome occurs coincident with long-range genetic and epigenetic alterations. Genome Res. 2016;26(6):719-31.

10. Hu Z, Chen K, Xia Z, Chavez M, Pal S, Seol JH, et al. Nucleosome loss leads to global transcriptional up-regulation and genomic instability during yeast aging. Genes Dev. 2014;28(4):396-408.

11. O'Sullivan RJ, Kubicek S, Schreiber SL, Karlseder J. Reduced histone biosynthesis and chromatin changes arising from a damage signal at telomeres. Nat Struct Mol Biol. 2010;17(10):1218-25.

12. Giles KA, Taberlay PC. Mutations in chromatin remodeling factors. In: Pfeifer G, editor. Encyclopedia of cancer. 3rd ed. United States: Elsevier; 2019. p. $511-27$.
13. Reisman D, Glaros $\mathrm{S}$, Thompson EA. The SWI/SNF complex and cancer. Oncogene. 2009;28(14):1653-68.

14. Shain AH, Pollack JR. The spectrum of SWI/SNF mutations, ubiquitous in human cancers. PLOS ONE. 2013;8(1):e55119.

15. Wilson BG, Roberts CW. SWI/SNF nucleosome remodellers and cancer. Nat Rev Cancer. 2011;11(7):481-92.

16. Chu X, Guo X, Jiang Y, Yu H, Liu L, Shan W, et al. Genotranscriptomic meta-analysis of the CHD family chromatin remodelers in human cancers - initial evidence of an oncogenic role for CHD7. Mol Oncol. 2017;11(10):1348-60.

17. Kadoch C, Hargreaves DC, Hodges C, Elias L, Ho L, Ranish J, et al. Proteomic and bioinformatic analysis of mammalian SWI/SNF complexes identifies extensive roles in human malignancy. Nat Genet. 2013;45(6):592-601.

18. Dunaief JL, Strober BE, Guha S, Khavari PA, Alin K, Luban J, et al. The retinoblastoma protein and BRG1 form a complex and cooperate to induce cell cycle arrest. Cell. 1994;79(1):119-30.

19. Strober BE, Dunaief JL, Guha GSP. Functional interactions between the hBRM/hBRG1 transcriptional activators and the pRB family of proteins. Mol Cell Biol. 1996;16(4):1576-83.

20. Yokoyama Y, Matsushita Y, Shigeto T, Futagami M, Mizunuma H. Decreased ARID1A expression is correlated with chemoresistance in epithelial ovarian cancer. J Gynecol Oncol. 2014;25(1):58-63.

21. Song S, Walter V, Karaca M, Li Y, Bartlett CS, Smiraglia DJ, et al. Gene silencing associated with SWI/SNF complex loss during NSCLC development. Mol Cancer Res: MCR. 2014;4:560-70.

22. Buscarlet M, Krasteva V, Ho L, Simon C, Hebert J, Wilhelm B, et al. Essential role of BRG, the ATPase subunit of BAF chromatin remodeling complexes, in leukemia maintenance. Blood. 2014;11:1720-8.

23. Yan $\mathrm{HB}$, Wang $X F$, Zhang $\mathrm{Q}$, Tang $\mathrm{ZQ}$, Jiang $\mathrm{YH}$, Fan $\mathrm{HZ}$, et al. Reduced expression of the chromatin remodeling gene ARID1A enhances gastric cancer cell migration and invasion via downregulation of E-cadherin transcription. Carcinogenesis. 2013:35:867-76.

24. Shi J, Whyte WA, Zepeda-Mendoza CJ, Milazzo JP, Shen C, Roe JS, et al. Role of SWI/SNF in acute leukemia maintenance and enhancer-mediated Myc regulation. Genes Dev. 2013;27(24):2648-62.

25. Romero OA, Torres-Diz M, Pros E, Savola S, Gomez A, Moran S, et al. MAX inactivation in small-cell lung cancer disrupts the MYC-SWI/SNF programs and is synthetic lethal with BRG1. Cancer Discov. 2013;3:292-303.

26. Oike T, Ogiwara H, Nakano T, Yokota J, Kohno T. Inactivating mutations in SWI/SNF chromatin remodeling genes in human cancer. Jpn J Clin Oncol. 2013:43(9):849-55.

27. Mao TL, Ardighieri L, Ayhan A, Kuo KT, Wu CH, Wang TL, et al. Loss of ARID1A expression correlates with stages of tumor progression in uterine endometrioid carcinoma. Am J Surg Pathol. 2013;37(9):1342-8.

28. Cho H, Kim JS, Chung H, Perry C, Lee H, Kim JH. Loss of ARID1A/ BAF250a expression is linked to tumor progression and adverse prognosis in cervical cancer. Hum Pathol. 2013;44(7):1365-74.

29. Bosse T, ter Haar NT, Seeber LM, van Diest PJ, Hes FJ, Vasen HF, et al. Loss of ARID1A expression and its relationship with PI3K-Akt pathway alterations, TP53 and microsatellite instability in endometrial cancer. Mod Pathol. 2013;26(11):1525-35.

30. Bai J, Mei P, Zhang C, Chen F, Li C, Pan Z, et al. BRG1 is a prognostic marker and potential therapeutic target in human breast cancer. PLoS ONE. 2013;8(3):e59772.

31. You JS, Jones PA. Cancer genetics and epigenetics: two sides of the same coin? Cancer Cell. 2012;22(1):9-20.

32. Katagiri A, Nakayama K, Rahman MT, Rahman M, Katagiri H, Nakayama $\mathrm{N}$, et al. Loss of ARID1A expression is related to shorter progression-free survival and chemoresistance in ovarian clear cell carcinoma. Mod Pathol. 2012;25(2):282-8.

33. Roberts CW, Biegel JA. The role of SMARCB1/INI1 in development of rhabdoid tumor. Cancer Biol Ther. 2009;8(5):412-6.

34. Roy DM, Walsh LA, Chan TA. Driver mutations of cancer epigenomes. Protein Cell. 2014;5(4):265-96.

35. Zhao J, Liu C, Zhao Z. ARID1A: a potential prognostic factor for breast cancer. Tumour Biol. 2014;35(5):4813-9.

36. Wong AK, Shanahan F, Chen Y, Lian L, Ha P, Hendricks K, et al. BRG1, a component of the SWI-SNF complex, is mutated in multiple human tumor cell lines. Cancer Res. 2000;60(21):6171-7. 
37. Medina PP, Romero OA, Kohno T, Montuenga LM, Pio R, Yokota J, et al. Frequent BRG1/SMARCA4-inactivating mutations in human lung cancer cell lines. Hum Mutat. 2008;29(5):617-22.

38. Roberts CW, Orkin SH. The SWI/SNF complex-chromatin and cancer. Nat Rev Cancer. 2004;4(2):133-42.

39. Wilson BG, Helming KC, Wang X, Kim Y, Vazquez F, Jagani Z, et al. Residual complexes containing SMARCA2 (BRM) underlie the oncogenic drive of SMARCA4 (BRG1) mutation. Mol Cell Biol. 2014;34(6):1136-44.

40. Herpel E, Rieker RJ, Dienemann H, Muley T, Meister M, Hartmann A, et al. SMARCA4 and SMARCA2 deficiency in non-small cell lung cancer: immunohistochemical survey of 316 consecutive specimens. Ann Diagn Pathol. 2017:26:47-51.

41. Agaimy A, Fuchs F, Moskalev EA, Sirbu H, Hartmann A, Haller F. SMARCA4-deficient pulmonary adenocarcinoma: clinicopathological, immunohistochemical, and molecular characteristics of a novel aggressive neoplasm with a consistent TTF1(neg)/CK7(pos)/HepPar1 (pos) immunophenotype. Virchows Arch. 2017;471(5):599-609.

42. Sun A, Tawfik O, Gayed B, Thrasher JB, Hoestje S, Li C, et al. Aberrant expression of SWI/SNF catalytic subunits BRG1/BRM is associated with tumor development and increased invasiveness in prostate cancers. Prostate. 2007;67(2):203-13.

43. Ding Y, Li N, Dong B, Guo W, Wei H, Chen Q, et al. Chromatin remodeling ATPase BRG1 and PTEN are synthetic lethal in prostate cancer. J Clin Invest. 2019;129(2):759-73.

44. Liu XB, Sun AJ, Wang C, Chen LR. Expression of BRG1 and BRM proteins in prostatic cancer. Zhonghua Bing Li Xue Za Zhi. 2010;39(9):591-4

45. Li Y, Shi QL, Jin XZ, Meng K, Zhou XJ, Sun LP. BRG1 expression in prostate carcinoma by application of tissue microarray. Zhonghua Nan Ke Xue. 2006;12(7):629-32.

46. Valdman A, Nordenskjold A, Fang X, Naito A, Al-Shukri S, Larsson C, et al. Mutation analysis of the BRG1 gene in prostate cancer clinical samples. Int J Oncol. 2003;22(5):1003-7.

47. Tagal V, Wei S, Zhang W, Brekken RA, Posner BA, Peyton M, et al. SMARCA4-inactivating mutations increase sensitivity to Aurora kinase A inhibitor VX-680 in non-small cell lung cancers. Nat Commun. 2017:8:14098.

48. Oike T, Ogiwara H, Tominaga Y, Ito K, Ando O, Tsuta K, et al. A synthetic lethality-based strategy to treat cancers harboring a genetic deficiency in the chromatin remodeling factor BRG1. Cancer Res. 2013;73(17):5508-18.

49. Muthuswami R, Bailey L, Rakesh R, Imbalzano AN, Nickerson JA, Hockensmith JW. BRG1 is a prognostic indicator and a potential therapeutic target for prostate cancer. J Cell Physiol. 2019;234(9):15194-205.

50. Cancer Genome Atlas Research N. The molecular taxonomy of primary prostate cancer. Cell. 2015;163(4):1011-25.

51. Tolstorukov MY, Sansam CG, Lu P, Koellhoffer EC, Helming KC, Alver $\mathrm{BH}$, et al. Swi/Snf chromatin remodeling/tumor suppressor complex establishes nucleosome occupancy at target promoters. Proc Natl Acad Sci USA. 2013:110(25):10165-70.

52. Alver BH, Kim KH, Lu P, Wang X, Manchester HE, Wang W, et al. The SWI/ SNF chromatin remodelling complex is required for maintenance of lineage specific enhancers. Nat Commun. 2017;8:14648.

53. Hodges HC, Stanton BZ, Cermakova K, Chang CY, Miller EL, Kirkland $J G$, et al. Dominant-negative SMARCA4 mutants alter the accessibility landscape of tissue-unrestricted enhancers. Nat Struct Mol Biol. 2018;25(1):61-72.

54. Hu G, Schones DE, Cui K, Ybarra R, Northrup D, Tang Q, et al. Regulation of nucleosome landscape and transcription factor targeting at tissuespecific enhancers by BRG1. Genome Res. 2011;21(10):1650-8.

55. Bao X, Rubin AJ, Qu K, Zhang J, Giresi PG, Chang HY, et al. A novel ATAC-seq approach reveals lineage-specific reinforcement of the open chromatin landscape via cooperation between BAF and p63. Genome Biol. 2015;16:284.

56. Giles KA, Gould CM, Du Q, Skvortsova K, Song JZ, Maddugoda MP, et al. Integrated epigenomic analysis stratifies chromatin remodellers into distinct functional groups. Epigenetics Chromatin. 2019;12(1):12.

57. Luebben WR, Sharma N, Nyborg JK. Nucleosome eviction and activated transcription require p300 acetylation of histone H3 lysine 14. Proc Natl Acad Sci USA. 2010;107(45):19254-9.
58. Morrison EA, Sanchez JC, Ronan JL, Farrell DP, Varzavand K, Johnson $\mathrm{JK}$, et al. DNA binding drives the association of BRG1/hBRM bromodomains with nucleosomes. Nat Commun. 2017:8:16080.

59. Shen W, Xu C, Huang W, Zhang J, Carlson JE, Tu X, et al. Solution structure of human Brg1 bromodomain and its specific binding to acetylated histone tails. Biochemistry. 2007;46(8):2100-10.

60. Church M, Smith KC, Alhussain MM, Pennings S, Fleming AB. Sas3 and Ada2(Gcn5)-dependent histone $\mathrm{H} 3$ acetylation is required for transcription elongation at the de-repressed FLO1 gene. Nucleic Acids Res. 2017;45(8):4413-30

61. Kim SI, Bresnick EH, Bultman SJ. BRG1 directly regulates nucleosome structure and chromatin looping of the alpha globin locus to activate transcription. Nucleic Acids Res. 2009;37(18):6019-27.

62. Kim SI, Bultman SJ, Kiefer CM, Dean A, Bresnick EH. BRG1 requirement for long-range interaction of a locus control region with a downstream promoter. Proc Natl Acad Sci USA. 2009;106(7):2259-64.

63. Bossen C, Murre CS, Chang AN, Mansson R, Rodewald HR, Murre C. The chromatin remodeler Brg1 activates enhancer repertoires to establish B cell identity and modulate cell growth. Nat Immunol. 2015;16(7):775-84.

64. Ni Z, Abou El Hassan M, Xu Z, Yu T, Bremner R. The chromatin-remodeling enzyme BRG1 coordinates CIITA induction through many interdependent distal enhancers. Nat Immunol. 2008;9(7):785-93.

65. Barutcu AR, Lajoie BR, Fritz AJ, McCord RP, Nickerson JA, van Wijnen AJ, et al. SMARCA4 regulates gene expression and higher-order chromatin structure in proliferating mammary epithelial cells. Genome Res. 2016;26(9):1188-201.

66. Dai Y, Ngo D, Jacob J, Forman LW, Faller DV. Prohibitin and the SWI/SNF ATPase subunit BRG1 are required for effective androgen antagonistmediated transcriptional repression of androgen receptor-regulated genes. Carcinogenesis. 2008;29(9):1725-33.

67. Marshall TW, Link KA, Petre-Draviam CE, Knudsen KE. Differential requirement of SWI/SNF for androgen receptor activity. J Biol Chem. 2003;278(33):30605-13.

68. Hoffman JA, Trotter KW, Ward JM, Archer TK. BRG1 governs glucocorticoid receptor interactions with chromatin and pioneer factors across the genome. Elife. 2018;7:e35073.

69. Prensner JR, lyer MK, Balbin OA, Dhanasekaran SM, Cao Q, Brenner JC, et al. Transcriptome sequencing across a prostate cancer cohort identifies PCAT-1, an unannotated lincRNA implicated in disease progression. Nat Biotechnol. 2011;29(8):742-9.

70. Andersson R, Enroth S, Rada-Iglesias A, Wadelius C, Komorowski J. Nucleosomes are well positioned in exons and carry characteristic histone modifications. Genome Res. 2009:19(10):1732-41.

71. Dhami P, Saffrey P, Bruce AW, Dillon SC, Chiang K, Bonhoure N, et al. Complex exon-intron marking by histone modifications is not determined solely by nucleosome distribution. PLoS ONE. 2010;5(8):e12339.

72. Huang H, Yu S, Liu H, Sun X. Nucleosome organization in sequences of alternative events in human genome. Bio Syst. 2012;109(2):214-9.

73. Shen S, Park JW, Huang J, Dittmar KA, Lu ZX, Zhou Q, et al. MATS: a Bayesian framework for flexible detection of differential alternative splicing from RNA-Seq data. Nucleic Acids Res. 2012;40(8):e61.

74. Shen S, Park JW, Lu ZX, Lin L, Henry MD, Wu YN, et al. rMATS: robust and flexible detection of differential alternative splicing from replicate RNASeq data. Proc Natl Acad Sci USA. 2014;111(51):E5593-601.

75. Park JW, Tokheim C, Shen S, Xing Y. Identifying differential alternative splicing events from RNA sequencing data using RNASeq-MATS. Methods Mol Biol. 2013;1038:171-9.

76. David A, Mabjeesh N, Azar I, Biton S, Engel S, Bernstein J, et al. Unusual alternative splicing within the human kallikrein genes KLK2 and KLK3 gives rise to novel prostate-specific proteins. J Biol Chem. 2002:277(20):18084-90.

77. Shang Z, Niu Y, Cai Q, Chen J, Tian J, Yeh S, et al. Human kallikrein 2 (KLK2) promotes prostate cancer cell growth via function as a modulator to promote the ARA70-enhanced androgen receptor transactivation. Tumour Biol. 2014;35(3):1881-90.

78. Lin KT, Gong J, Li CF, Jang TH, Chen WL, Chen HJ, et al. Vav3-rac1 signaling regulates prostate cancer metastasis with elevated Vav3 expression correlating with prostate cancer progression and posttreatment recurrence. Cancer Res. 2012;72(12):3000-9. 
79. Liu Y, Mo JQ, Hu Q, Boivin G, Levin L, Lu S, et al. Targeted overexpression of vav3 oncogene in prostatic epithelium induces nonbacterial prostatitis and prostate cancer. Cancer Res. 2008;68(15):6396-406.

80. Lyons LS, Burnstein KL. Vav3, a Rho GTPase guanine nucleotide exchange factor, increases during progression to androgen independence in prostate cancer cells and potentiates androgen receptor transcriptional activity. Mol Endocrinol. 2006;20(5):1061-72.

81. Prensner JR, Chen W, Han S, lyer MK, Cao Q, Kothari V, et al. The long non-coding RNA PCAT-1 promotes prostate cancer cell proliferation through cMyc. Neoplasia. 2014;16(11):900-8.

82. Rao S, Lyons LS, Fahrenholtz CD, Wu F, Faroog A, Balkan W, et al. A novel nuclear role for the Vav3 nucleotide exchange factor in androgen receptor coactivation in prostate cancer. Oncogene. 2012;31(6):716-27.

83. Shang Z, Yu J, Sun L, Tian J, Zhu S, Zhang B, et al. LncRNA PCAT1 activates AKT and NF-kappaB signaling in castration-resistant prostate cancer by regulating the PHLPP/FKBP51//KKalpha complex. Nucleic Acids Res. 2019;47(8):4211-25.

84. Williams SA, Xu Y, De Marzo AM, Isaacs JT, Denmeade SR. Prostatespecific antigen (PSA) is activated by KLK2 in prostate cancer ex vivo models and in prostate-targeted PSA/KLK2 double transgenic mice. Prostate. 2010;70(7):788-96.

85. Chen EY, Tan CM, Kou Y, Duan Q, Wang Z, Meirelles GV, et al. Enrichr: interactive and collaborative HTML5 gene list enrichment analysis tool. BMC Bioinform. 2013;14:128.

86. Kuleshov MV, Jones MR, Rouillard AD, Fernandez NF, Duan Q, Wang $Z$, et al. Enrichr: a comprehensive gene set enrichment analysis web server 2016 update. Nucl Acids Res. 2016;44(W1):W90-7.

87. Gui B, Gui F, Takai T, Feng C, Bai X, Fazli L, et al. Selective targeting of PARP-2 inhibits androgen receptor signaling and prostate cancer growth through disruption of FOXA1 function. Proc Natl Acad Sci USA 2019:116(29):14573-82

88. Jones D, Wade M, Nakjang S, Chaytor L, Grey J, Robson CN, et al. FOXA1 regulates androgen receptor variant activity in models of castrateresistant prostate cancer. Oncotarget. 2015;6(30):29782-94.

89. Andreu-Vieyra C, Lai J, Berman BP, Frenkel B, Jia L, Jones PA, et al. Dynamic nucleosome-depleted regions at androgen receptor enhancers in the absence of ligand in prostate cancer cells. Mol Cell Biol. 2011:31(23):4648-62.

90. Chen Z, Lan X, Thomas-Ahner JM, Wu D, Liu X, Ye Z, et al. Agonist and antagonist switch DNA motifs recognized by human androgen receptor in prostate cancer. EMBO J. 2015;34(4):502-16.

91. Ye Z, Chen Z, Sunkel B, Frietze S, Huang TH, Wang Q, et al. Genomewide analysis reveals positional-nucleosome-oriented binding pattern of pioneer factor FOXA1. Nucl Acids Res. 2016;44(16):7540-54.
92. Stelloo S, Nevedomskaya E, Kim Y, Hoekman L, Bleijerveld OB, Mirza $T$, et al. Endogenous androgen receptor proteomic profiling reveals genomic subcomplex involved in prostate tumorigenesis. Oncogene. 2018;37(3):313-22.

93. Nacht AS, Pohl A, Zaurin R, Soronellas D, Quilez J, Sharma P, et al. Hormone-induced repression of genes requires BRG1-mediated $\mathrm{H} 1.2$ deposition at target promoters. EMBO J. 2016:35(16):1822-43.

94. Strobeck MW, Knudsen KE, Fribourg AF, DeCristofaro MF, Weissman BE, Imbalzano AN, et al. BRG-1 is required for RB-mediated cell cycle arrest. Proc Natl Acad Sci USA. 2000;97(14):7748-53.

95. Zhang HS, Gavin M, Dahiya A, Postigo AA, Ma D, Luo RX, et al. Exit from $\mathrm{G} 1$ and $S$ phase of the cell cycle is regulated by repressor complexes containing HDAC-Rb-hSWI/SNF and Rb-hSWI/SNF. Cell. 2000:101(1):79-89.

96. Naidu SR, Love IM, Imbalzano AN, Grossman SR, Androphy EJ. The SWI/SNF chromatin remodeling subunit BRG1 is a critical regulator of $\mathrm{p} 53$ necessary for proliferation of malignant cells. Oncogene. 2009;28(27):2492-501.

97. Pomerantz MM, Li F, Takeda DY, Lenci R, Chonkar A, Chabot M, et al. The androgen receptor cistrome is extensively reprogrammed in human prostate tumorigenesis. Nat Genet. 2015;47(11):1346-51.

98. Sobczak M, Pietrzak J, Ploszaj T, Robaszkiewicz A. BRG1 activates proliferation and transcription of cell cycle-dependent genes in breast cancer cells. Cancers (Basel). 2020;12(2):349.

99. Rueden CT, Schindelin J, Hiner MC, DeZonia BE, Walter AE, Arena ET, et al. Image J2: ImageJ for the next generation of scientific image data. BMC Bioinform. 2017;18(1):529.

100. Schneider CA, Rasband WS, Eliceiri KW. NIH Image to ImageJ: 25 years of image analysis. Nat Methods. 2012;9(7):671-5.

101. Liao Y, Smyth GK, Shi W. featureCounts: an efficient general purpose program for assigning sequence reads to genomic features. Bioinformatics. 2014;30(7):923-30.

102. Bert SA, Robinson MD, Strbenac D, Statham AL, Song JZ, HulfT, et al. Regional activation of the cancer genome by long-range epigenetic remodeling. Cancer Cell. 2013;23(1):9-22.

103. Ramirez F, Ryan DP, Gruning B, Bhardwaj V, Kilpert F, Richter AS, et al. deepTools2: a next generation web server for deep-sequencing data analysis. Nucl Acids Res. 2016:44(W1):W160-5.

\section{Publisher's Note}

Springer Nature remains neutral with regard to jurisdictional claims in published maps and institutional affiliations.
Ready to submit your research? Choose BMC and benefit from:

- fast, convenient online submission

- thorough peer review by experienced researchers in your field

- rapid publication on acceptance

- support for research data, including large and complex data types

- gold Open Access which fosters wider collaboration and increased citations

- maximum visibility for your research: over 100M website views per year

At $B M C$, research is always in progress.

Learn more biomedcentral.com/submissions 